\title{
Nursing Clinical Instructor Experiences of Empowerment in Rwanda: Applying Kanter's and Spreitzer's Theories
}

Mary E. Thuss, The University of Western Ontario

Supervisor: Dr. Yolanda Babenko-Mould, The University of Western Ontario

A thesis submitted in partial fulfillment of the requirements for the Master of Science degree in Nursing

(C) Mary E. Thuss 2014

Follow this and additional works at: https://ir.lib.uwo.ca/etd

Part of the Nursing Commons

\section{Recommended Citation}

Thuss, Mary E., "Nursing Clinical Instructor Experiences of Empowerment in Rwanda: Applying Kanter's and Spreitzer's Theories" (2014). Electronic Thesis and Dissertation Repository. 2180.

https://ir.lib.uwo.ca/etd/2180

This Dissertation/Thesis is brought to you for free and open access by Scholarship@Western. It has been accepted for inclusion in Electronic Thesis and Dissertation Repository by an authorized administrator of Scholarship@Western. For more information, please contact wlswadmin@uwo.ca. 


\title{
NURSING CLINICAL INSTRUCTOR EXPERIENCES OF EMPOWERMENT IN RWANDA: APPLYING KANTER'S AND SPREITZER'S THEORIES
}

(Thesis format: Integrated Article)

by

\author{
Mary E. Thuss
}

Graduate Program in Nursing

A thesis submitted in partial fulfillment

of requirements for the degree of

Master of Science in Nursing

The School of Graduate and Postdoctoral Studies

Western University

London, Ontario, Canada

CMary E. Thuss 2014 


\begin{abstract}
Clinical instructors (CIs) play a vital role in students' development by facilitating learning in various health care practice environments. Quality nursing education hinges on the CI's ability to enact his or her professional role. The purpose of this study was to explore Rwandan nursing clinical instructors' experiences of structural and psychological empowerment.

A descriptive qualitative method was used to obtain an understanding of CIs empowerment experiences in practice settings. Kanter's (1993) Theory of Structural Power in Organizations and Spreitzer's (1995) Psychological Empowerment Theory were used as a theoretical framework to interpret their experiences. Interview data from 21 nursing CIs in Rwanda were used to complete a secondary data analysis for this study.

Most study participants perceived the structural components of informal power, resources, and support while formal power and opportunity were limited, diminishing their sense of structural empowerment. Psychological empowerment for the CIs in Rwanda stemmed from a sense of competence, meaning, impact and self-determination they had for their teaching roles and responsibilities in the practice setting. Implications and recommendations for CIs and administration are suggested to support, recruit and retain clinical instructors.
\end{abstract}

\title{
Keywords
}

Clinical instructors, clinical educators, clinical instructors' role, nursing education, Kanter, structural empowerment, Spreitzer, psychological empowerment. 


\section{CO-AUTHORSHIP STATEMENT}

Mary Thuss completed the following work under the supervision of Dr. Yolanda

Babenko-Mould, Dr. Mary-Anne Andrusyszyn and Dr. Heather Laschinger who will be coauthors on the publication resulting from the manuscript. 


\section{ACKNOWLEDGMENTS}

This thesis dissertation is a result of contributions of a number of people who I would like to acknowledge. I extend my heartfelt appreciation and gratitude to my thesis advisor Dr. Yolanda Babenko-Mould for her valued support. She fostered personal and professional growth with expert feedback and guidance and helped me stay focused and motivated throughout the dissertation process. I would also like to acknowledge my advisory committee members Drs. Mary-Anne Andrusyszyn and Heather Laschinger for their respected mentorship and support.

The completion of this dissertation could not have been possible without the support of my graduate study colleagues. Maria Lozada, Nicole LeBlanc, Sandra Wiens and Mona Groenewegen-Beukeboom helped me navigate through the demands of the graduate program and contributed to my success as a life-long learner. My friends and working colleagues Helen Myles and Wilma Koopman constantly monitored my health and well-being as I spent long hours working towards the completion of this degree! I would also like to thank Eileen Hanna whose confidence in my ability to achieve my life long goal spurred me in this educational direction and sustained me.

Also a special and deep felt thanks to my parents for always believing in me and encouraging me in all my endeavors. I thank you for passing on to me your sense of faith, determination and ability to organize and manage the multiple tasks of a busy household. These qualities have helped me achieve my personal and professional goals. And finally my deepest appreciation goes to my husband Gerry for his love and support and to our three children, Andrew, Adam and Jennifer who are the source of my pride and joy. 


\section{TABLE OF CONTENTS}

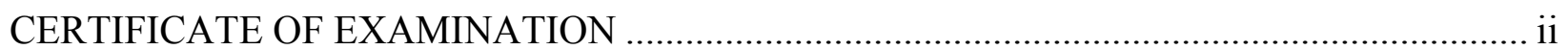

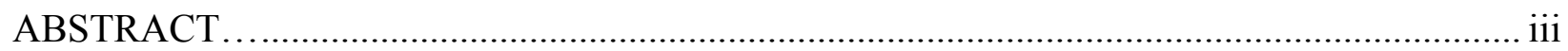

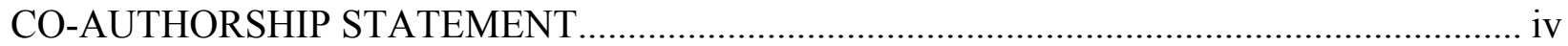

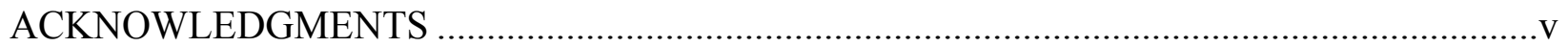

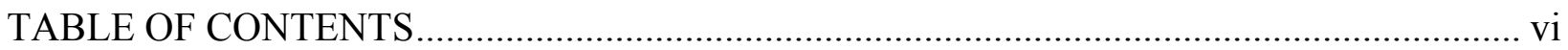

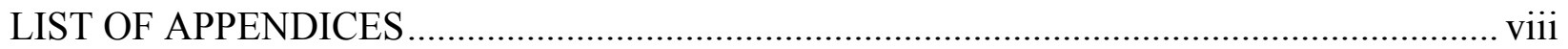

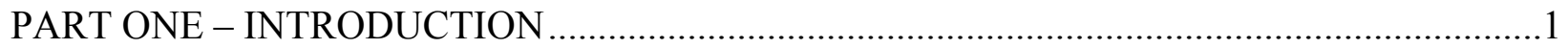

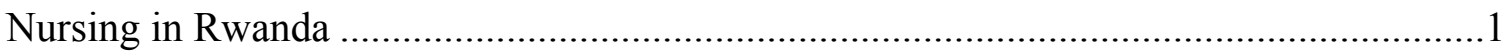

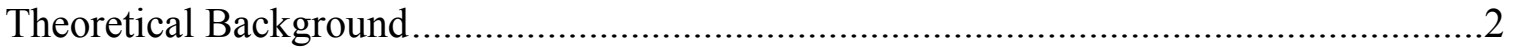

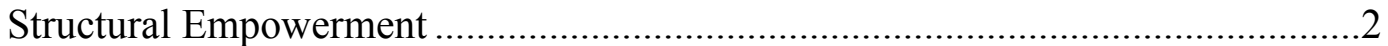

Psychological Empowerment......................................................................... 3

Integration of Structural and Psychological Empowerment .................................

Structural and Psychological Empowerment in Nursing ...................................4

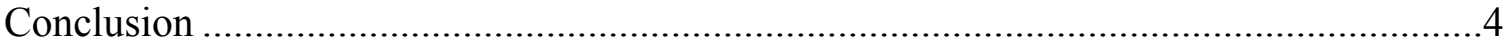

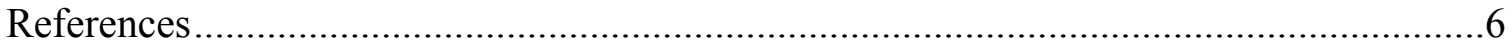

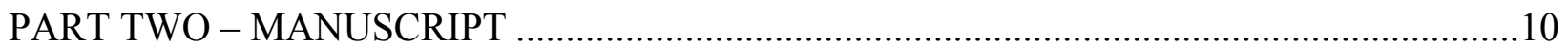

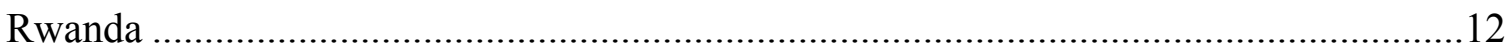

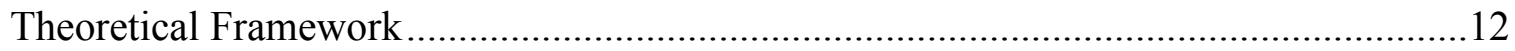

Overview of Kanter's Theory of Structural Power in Organizations .....................12

Overview of Spreitzer's Theory of Psychological Empowerment .......................12

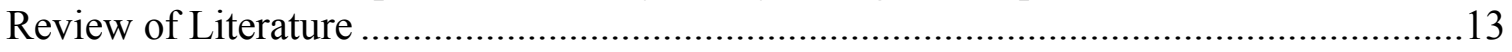

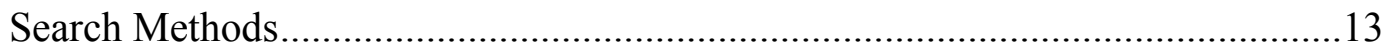

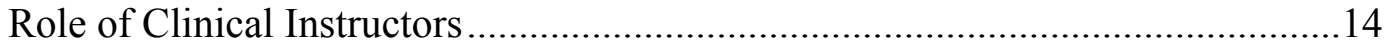

Structural Empowerment and the Nursing Literature ........................................ 15

Psychological Empowerment and the Nursing Literature ................................... 15

Expanded Empowerment Model and the Nursing Literature .............................16

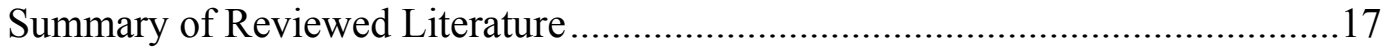

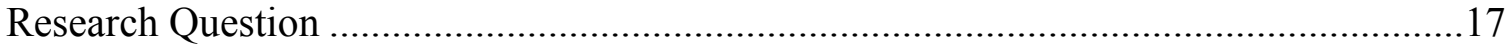

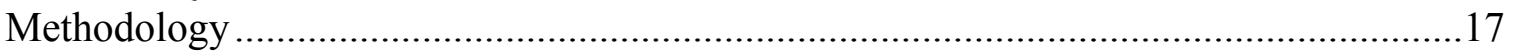

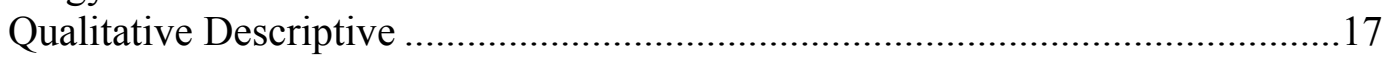

Qualitative Description - Study Design and Method ....................................... 18

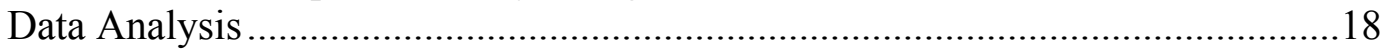

Approaches for Creating Quality Research ..................................................18

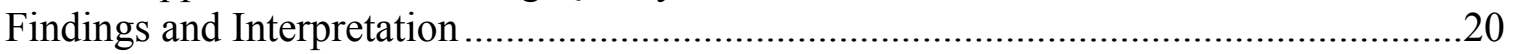

Findings Related to Structural Empowerment ..............................................20

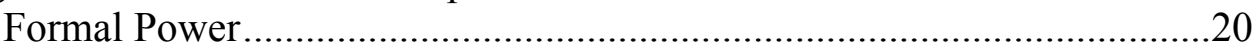

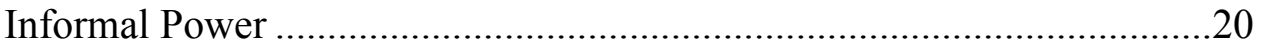

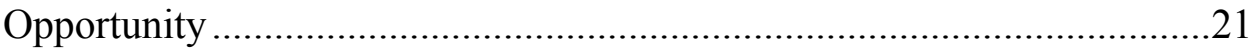

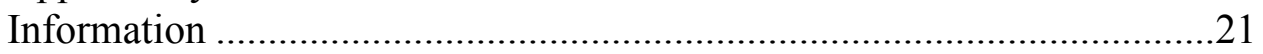




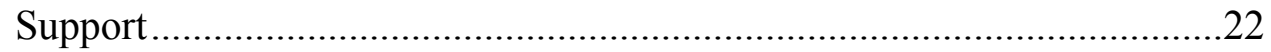

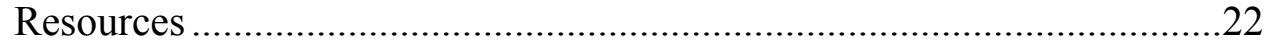

Findings Related to Psychological Empowerment ..............................................23

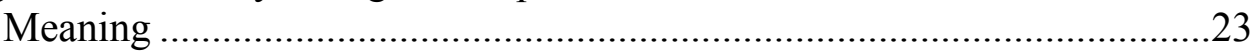

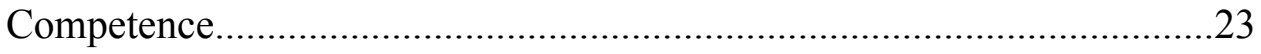

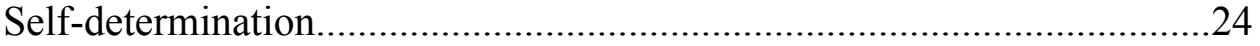

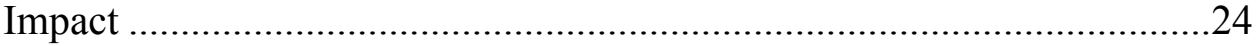

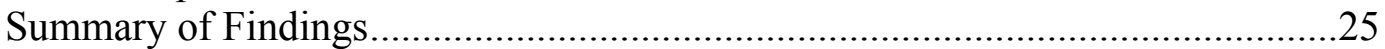

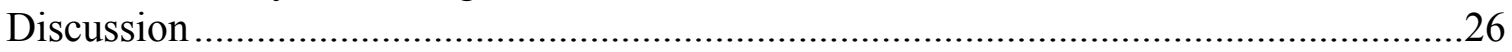

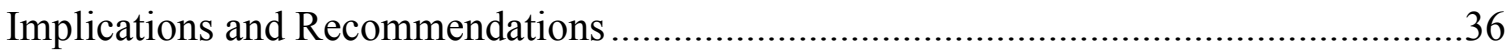

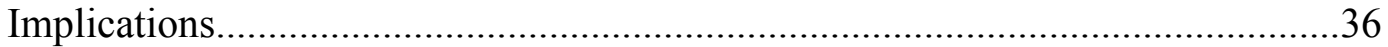

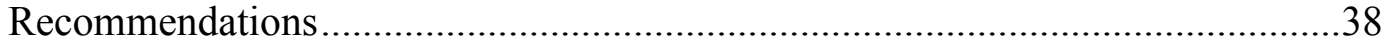

Recommendations for Further Research...........................................................39

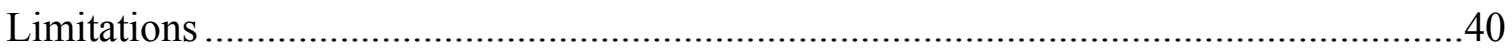

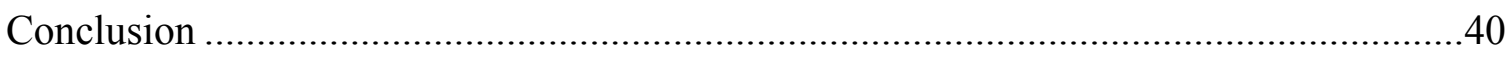

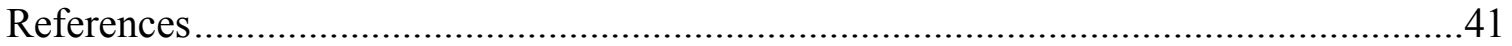

PART THREE - IMPLICATIONS, RECOMMENDATIONS, AND CONCLUSION ..............49

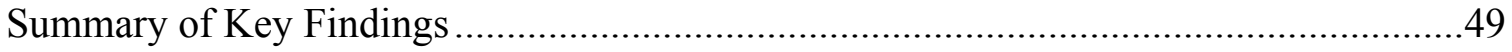

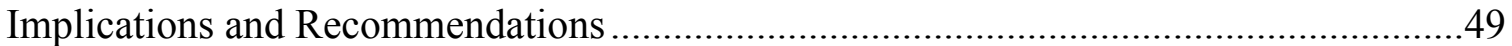

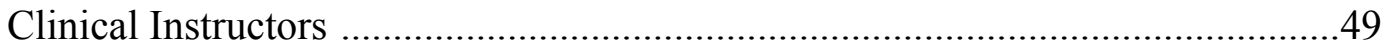

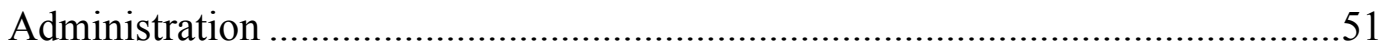

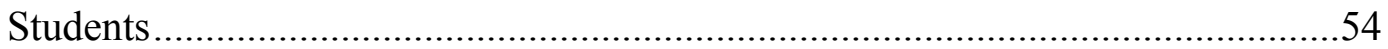

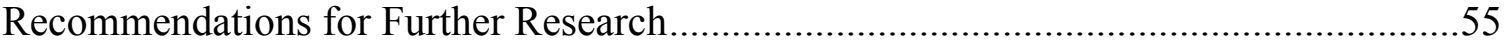

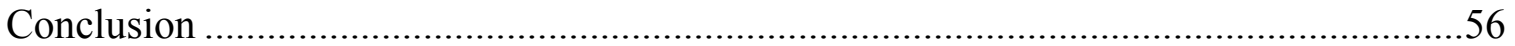

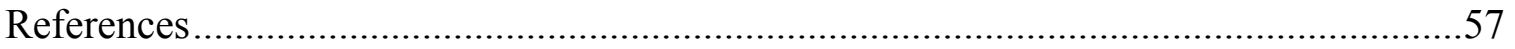

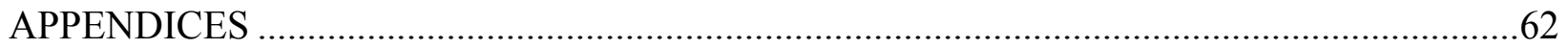

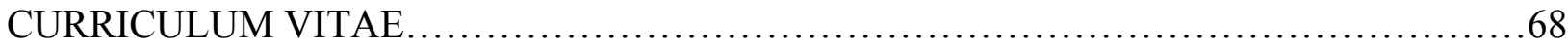




\section{LIST OF APPENDICES}

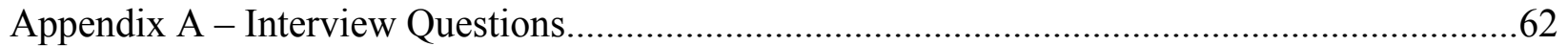

Appendix B - Office of Research Ethics-Ethics Approval Notice..........................................64

Appendix C - Kigali Health Institute-Expedited Ethics Clearance.........................................65

Appendix D -Letter of Information for Clinical Instructors .............................................66 


\section{PART ONE INTRODUCTION}

Clinical instructors (CIs) play a vital role in nursing students' development enabling them to gain self-confidence for future practice (Eta, Atanga, Atashill, \& D'Cruz, 2011; Hayajneh, 2010). Clinical instructors are the teaching faculty that guide nursing students to gain fundamental knowledge, technical skills, and practice values (Gaberson \& Oermann, 2010). They also play a significant role in creating positive learning experiences in the practice setting that frame student perceptions of the work environment (Freeman, 2012). The practice setting is where CIs facilitate student learning in various health care environments such as long-term care facilities, acute care hospitals and homecare/community services.

\section{Nursing in Rwanda}

In many African countries, nurses and midwives, who are the most in-demand health care professionals in the country, often work with limited support and reward (Klopper \& Uys, 2013). Many of these professionals are women and are often impacted by the weak position of nurses and midwives in African societies, potentially limiting their ability to engage in delivering quality care and implementing policies (Klopper \& Uys, 2013). In east-central Africa, the country of Rwanda is experiencing a critical shortage of nurses and nursing faculty due, in large part, to the genocide which occurred in 1994 and lead to the loss of approximately 800,000 lives (Rosenberg, 2012). The critical shortage of health professionals has resulted in only $30 \%$ of health facilities being able to meet minimum staffing needs (Africa Health Workforce Observatory [AHWO], 2009). A significant factor contributing to the shortage of professional nurses is the insufficient numbers of qualified nursing faculty (Rukholm et al., 2009); many migrating to countries away from their own to seek higher wages, better research funding and career growth (Sigma Theta Tau International [STTI], 2010). Therefore, in the country of Rwanda there is a significant need to educate, recruit, and retain nursing faculty.

In both developed and emerging countries, CIs face many challenges, including limited opportunities to update knowledge and skills (Eta et al., 2011); a need for additional educational resources (Brajtman, Fotergill-Bourbonnais, Fiest, \& Alain, 2009); and clinical workplace disputes (Shahsavari, Parsa Yekta, Houser, \& Ghiyasvandian, 2013). Support in the form of educational programs and ongoing up-to-date advances in nursing practice can positively impact CIs' ability to carry out their roles and responsibilities, improve teaching outcomes (Eta et al., 
2011) and enhance role effectiveness (Harerimana \& de Beer, 2013; Hunt, Curtis, \& Sanderson, 2013). To effectively utilize teaching strategies that promote competencies for nursing students, faculty need to be supported by the academic organization and practice settings that will ultimately empower them in their teaching role (Harerimana \& de Beer, 2013). If CIs perceive that the academic organization or practice setting does not support them in their role, does not value them in their jobs, or provide opportunities for ongoing development, a sense of empowerment may be limited, ultimately negatively influencing job satisfaction and commitment to the organization. In Rwanda, where there is an essential need for additional competent nurse educators, it is important to gain an understanding of the challenges experienced by the CIs in their role as educators, by conducting research in the area of CIs' empowerment.

There has been limited research to date that has been conducted exploring the experiences of empowerment, both structural empowerment (SE) (Kanter, 1993) and psychological empowerment (PE) (Spreitzer, 1995) with CIs who facilitate students' learning in practice environments. Therefore, the purpose of this study was to explore the ways in which nursing clinical instructors in Rwanda described their experiences of structural (opportunity, information, support, resources, formal, and informal power) and psychological (meaning, competence, self-determination, and impact) empowerment. Guided by the integrated model of empowerment (Laschinger, Finegan, Shamian, \& Wilk, 2001), a qualitative descriptive study was conducted using data collected in 2011 from interviews of clinical instructors in Rwanda. An exploration of CIs empowerment can provide insight into how CIs effectively engage in their role as facilitators of students' learning in the practice environment.

\section{Theoretical Background}

\section{Structural Empowerment}

According to Kanter's (1993) theory of structural power in organizations, formal and informal power, access to information, opportunity for growth, support and resources can promote employee empowerment resulting in positive organizational outcomes such as job satisfaction and reduced job burnout (Gilbert, Laschinger, \& Leiter, 2010; Pineau Stam, Laschinger, Regan, \& Wong, 2013; Laschinger, 2008). Research has shown that nurses who felt empowered in their jobs were more committed to their organizations thereby increasing their intent to stay in their positions (Hauck, Quinn, \& Joyce, 2011). Smith, Leask Capitulo, Quinn Griffin, and Fitzpatrick (2012) recommended nurse leaders need to be aware of the factors to 
promote nurse empowerment that enhances role effectiveness, supports quality patient care, and the achievement of organizational outcomes. In an educational context (US), Hebenstreit's (2012) study findings demonstrated a positive link between SE and innovative behaviour among 221 nurse educators in baccalaureate nursing programs in the United States (US). Innovative behaviour is characterized by one's ability to initiate change and adapt to new situations, behaviours and attitudes that can create positive work environments (Hebenstreit).

\section{Psychological Empowerment}

Psychological empowerment (PE) as defined by Spreitzer (1995) is a motivational construct exhibited through four dimensions: meaning, competence, self-determination, and impact. According to Spreitzer (2007), PE refers to a number of psychological states individuals must experience to gain a sense of control within their work environment. PE has been associated with job satisfaction and reduced job stress (Chung \& Kowalski, 2012; Leggat, Bartram, Casimir, \& Stanton, 2010) and can potentially affect the recruitment and retention of employees. For 139 associate degree-nursing educators from 74 public community colleges in California, experienced PE was most strongly correlated with job satisfaction (Baker, Fitzpatrick, Quinn Griffin, 2011). Chung and Kowalski's (2012) study that surveyed 959 full-time nursing faculty in the US showed a positive link between mentoring quality, PE and ultimately job satisfaction. Therefore the authors recommended mentoring as an empowering strategy to support, recruit and retain nursing faculty.

\section{Integration of Structural and Psychological Empowerment}

According to Spreitzer (2007), to have a fuller understanding of empowerment in the workplace, integration of both structural and psychological empowerment perspectives is needed. This combines both the organizationally focused SE and individually centered PE. The working conditions within an organization can be described by the presence or absence of empowering structural conditions. On the other hand, PE is based on the employees' reaction to these conditions and influences attitudes and behaviors (Laschinger, Finegan, Shamian, \& Wilk, 2001; Laschinger, Finegan, \& Wilk, 2009). To promote positive change within organizations, Spreitzer argues that organizations need to gain a better understanding of how SE can assist in building employees' PE, and conversely, how positive attitudes and behaviors characterized by PE can promote the development of SE. 


\section{Structural and Psychological Empowerment in Nursing}

Integrating both Kanter's (1993) SE and Spreitzer's (1995) PE theories in nursing research has realized a number of key outcomes. Job satisfaction and job commitment were positively associated with perceived SE and PE empowerment with public health nurses (Chang, Lui, \& Yen, 2008), nurse educators (Baker, Fitzpatrick, \& Griffin, 2011), staff nurses (Laschinger, Finegan, \& Wilk, 2009; Smith, Andrusyszyn, \& Laschinger, 2010). Job strain and job burnout were reduced when nursing staff was structurally and psychologically empowered in their professional positions (Laschinger, Finegan, Shamain, \& Wilk, 2001; O’Brien, 2011). Wiens, Babenko-Mould, and Iwasiw (2014) also integrated both SE and PE theories of empowerment in a qualitative study that demonstrated all empowerment components were important for CIs in their role as faculty members in the academic setting.

Research has shown sufficient support for the utilization of both SE and PE theories in nursing and nursing education. It is therefore reasonable to propose the use of Kanter's (1993) SE and Spreitzer's (1995) theories as explanatory frameworks to describe CIs perceptions of their practice work environment. Thus, CIs' expressed knowledge for practice teaching and descriptions of their roles and responsibilities will be explored for perceptions of structural and psychological empowerment.

\section{Conclusion}

If the goal of many governments experiencing health human resource shortages is to increase accessibility and quality of health services, an increase in the number of healthcare professionals is needed to achieve this goal. Ways in which to do this include increasing the numbers of nurse educators and examining factors that can lead to teacher empowerment. Given that empowerment has been reported to enhance job satisfaction and lower rates of job burnout, it will have an important role to play in defining ways to retain and recruit nurses to become faculty members, such as clinical instructors. For the future delivery of quality health care, and development of the nursing profession, it is important that nurse educators introduce and highlight the concept of empowerment in their education programs (Brancato, 2007), and educational institutions develop opportunities for teaching faculty to influence and impact the nursing programs (Baker, Fitzpatrick, \& Griffin, 2011).

There is limited research literature globally that focuses on CIs' experiences of empowerment in the practice environment (Babenko-Mould, Iwasiw, Andrusyszyn, Laschinger, 
\& Weston,W. 2012a; Babenko-Mould, Iwasiw, Andrusyszyn, Laschinger, \&Weston, 2012b). Therefore the objective of this study was to explore nursing CI experiences of SE and PE in a Rwandan educational context as they engage in their role as facilitators of students' learning. As suggested by Smith, Leask Capitulo, Quinn Griffin, and Fitzpatrick (2012), nurse leaders need to be aware of the factors that empower nurses thereby enabling them to effectively engage in their professional role. Research into the perceptions of empowerment of CIs in Rwanda may assist administrators' understanding of the CI role and highlight factors that can build faculty empowerment ultimately enhancing teaching effectiveness and student learning experiences in the clinical setting. 


\section{References}

Africa Health Workforce Observatory (AHWO) (2009). Human resources for health country profile: Rwanda. Retrieved from http://www.hrh-observatory. afro.who.int/images/Document_Center/rwanda_hrh_country profile.pdf

Baker, S., Fitzpatrick, J., \& Griffin, M. (2011). Empowerment and job satisfaction in associate degree nurse educators. Nursing Education Perspectives, 32, 234-240. doi: 10.5480/1536-5026-32.4.234

Babenko-Mould, Y., Iwasiw, C., Andrusyszyn, M. A., Laschinger, H. K. S., \& Weston, W. (2012a). Nursing students' perceptions of clinical teachers' use of empowering teaching behaviours: Instrument psychometrics and application. International Journal of Nursing Education Scholarship, 9, 1-16. doi.org/10.1515/1548-923X.2245

Babenko-Mould, Y., Iwasiw, C., Andrusyszyn, M. A, Laschinger, H. K. S., \& Weston, W. (2012b). Effects of clinical practice environments on clinical teacher and nursing student outcomes. Journal of Nursing Education, 51, 217-225. doi: 10.3928/0148483420120323-06

Brajtman, S., Fothergill-Bourbonnais, F., Fiset, V., \& Alain, D. (2009). Survery of educators'end-of-life care learning needs in a Canadian baccalaureate nursing programme. International Journal of Palliative Nursing, 15, 170-178. Retrieved from http://www.relais.lib.uwo.ca:8080/posttoweb/servlet/DownloadDocument? 14724 30.pdf

Brancato, V. (2007). Psychological empowerment and use of empowering teaching behaviors among baccalaureate nursing faculty. Journal of Nursing Education, 46, 537544. Retrieved from http://www.healio.com/journals/jne

Chang, L., Liu, C., \& Yen, E. (2008). Effects of an empowerment-based education program for public health nurses in Taiwan. Journal of Clinical Nursing, 17, 2782-2790. doi: 1111/j.1365-2702.2008.02387.x

Chung, C., \& Kowalski, S. (2012). Job stress, mentoring, psychological empowerment, and job satisfaction among nursing faculty. Journal of Nursing Education, 51, 381-388. Retrieved from http://www.healio.com/journals/jne 
Eta, V., Atanga, M., Atashili, J., \& D’Cruz, G. (2011). Nurses and challenges faced as clinical educators: A survey of a group of nurses in Cameroon. PanAfrican Medical Journal, 8, 28-32. Retrieved from http://www.ncbi.nlm.nih.gov/pmc/ articles/PMC3201592/pdf/pamj-8-28.pdf

Freeman, M., Baumann, A., Akhtar-Danesh, N., Blythe, J., \& Fisher, A. (2012). Employment goals, expectations, and migration intentions of nursing graduates in a Canadian border city: A mixed methods study. International Journal of Nursing Studies, 49, 1531-1543. http://dx.doi.org/10.1016/j.ijnurstu.2012.07.015

Gaberson, K., \& Oermann, M. (2010). Clinical teaching strategies in nursing, $3^{\text {rd }}$ ed. New York, NY: Springer

Gilbert, S., Laschinger, H. K. S., \& Leiter, M. (2010). The mediating effect of burnout on the relationship between structural empowerment and organizational citizenship behaviours. Journal of Nursing Management, 18, 339-348. doi: 10.1111/j.13652834.2010.01074.

Harerimana, A., \& de Beer, J. (2013). Nurse educators' utilization of different teaching strategies in a competency-based approach in Rwanda. Africa Journal of Nursing and Midwifery, 15, 29-41. Retrieved from http://www.relais.lib.uwo.ca:8080/ posttoweb/servlet/DownloadDocument?8869845.pdf

Hauck, A., Quinn Griffin, M., \& Joyce, J. (2011). Structural empowerment and anticipated turnover among critical care nurses. Journal of Nursing Management, 19, 269-276. doi: 10.1111/j.1365-2834.2011.01205.x

Hayajneh, F. (2010). Role model clinical instructor as perceived by Jordanian nursing students. Journal of Research in Nursing, 16, 23-32. doi: 10.1177/ 1744987110364326.

Hunt, C., Curtis, A., \& Sanderson, B. (2013). A program to provide resources and Support for clinical associates. The Journal of Continuing Education, 44, 269 273. doi: 103928/00220124-20130402-27

Kanter, R. (1993). Men and women of the corporation, ( $2^{\text {nd }}$ ed.). New York: Basic Books. Klopper, H., \& Uys, L. (2013). The state of nursing and nursing education in Africa a country-by-country review. Sigma Theta Tau International Honor Society of Nursing. Retrieved from http://lib.myilibrary.com.proxy1.lib.uwo.ca/ ProductDetail.aspx $? \mathrm{id}=494002$ 
Laschinger, H. K. S., (2008). Effect of empowerment on professional practice environments, work satisfaction, and patient care quality further testing the nursing worklife model. Journal of Nursing Care Quality, 23, 322-330. doi: 10.1097/01.NCQ.0000318028.67910

Laschinger, H. K. S., Finegan, J., Shamain, J., \& Wilk, P. (2001). Impact of structural and psychological empowerment on job strain in nursing work settings: Expanding Kanter's Model. Journal of Nursing Administration, 31, 260, 272.

Laschinger, H., K. S., Finegan, J., \& Wilk, P. (2009). Context matters: The impact of unit leadership and empowerment on nurses' organizational commitment. Journal of Nursing Administration, 39, 228-235. doi: 10.1097/NNA.0b013e3181a23d2b

Leggat, S., Bartram, T., Casimir, G., \& Stanton, P. (2010). Nurse perceptions of the quality of patient care: Confirming the importance of empowerment and job satisfaction. Health Care Management Review, 35, 355-364. doi: 10.1097/HMR.0b013e3181e4ec55

O’Brien, J. (2011). Relationships among structural empowerment, psychological empowerment, and burnout in registered nurses working in outpatient dialysis centers. Nephrology Nursing Journal, 38, 475-481. Retrieved from https://www.google.ca/?gws_rd=ssl\#q=nephrology+nursing + journal

Pineau Stam, L., Laschinger, H. K. S., Regan, S., \& Wong, C. (2013). The influence of personal and workplace resources on new graduate nurses' job satisfaction. Journal of Nursing Management. doi: 10.1111/jonm.12113 [Epub ahead of print]

Rosenberg, J. (2012). Rwanda genocide: A short history of the Rwanda genocide. Retrieved from http://history1900s.about.com/od/rwandangenocide/a/RwandaGenocide.htm

Rukholm, E., Leesebert Stamler, L., Talbot, L.R., Bednash, G., Raines, F., Potempa, K., Nugent, P., Clark, D., Bernhauser, S., \&Parfitt, B. (2009). Scaling up the global nursing health workforce: Contributions of an international organization. Journal of the Royal College of Nursing Australia 16 (1), 41e45. doi: 10.1016/ j.colegn.2009.01.001

Shahsavari, H., Parsa Yekta, Z., Houser, M., \& Ghiyasvandian, S. (2013). Perceived clinical constraints in the nurse student-instructor interactions: A qualitative study. Nurse Education in Practice, 13, 546-552. Retrieved from http://dx.doi.org/10.1016/j.nepr.2013.05.006 
Sigma Theta Tau International Honor Society of Nursing (STTI) (2010). Salaries, Demand and Career Opportunities Contribute to Global Nursing Faculty Migration. Retrieved from: http://www.nursingsociety.org/Media/Pages/ Faculty_Summit.aspx

Smith, L., Andrusyszyn, M., \& Laschinger, H. K. S., (2010). Effects of workplace incivility and empowerment on newly-graduated nurses' organizational commitment. Journal of Nursing Management, 18, 1004-1015. doi: 10.1111/j.13652834.2010.01165.x

Smith, T., Leask Capitulo, K., Quinn Griffin, M., \& Fitzpatrick, J. (2012). Structural empowerment and anticipated turnover among behavioural health nurses. Journal of Nursing Management, 20, 679-684. doi: 10.1111/j.13652834.2012.01384.

Spreitzer, G. (1995). Psychological empowerment in the workplace: Dimensions, measurement, and validation. Academy of Management Journal, 38, 1442-1465. Retrieved from http://webuser.bus.umich.edu/spreitze/PsychEmpowerment.pdf management $\% 20 \mathrm{ob} \% 20$ handbook\%20final.pdf.

Spreitzer, G. (2007). Towards the integration of two perspectives: A review of socialstructural and psychological empowerment at work. For publication in Cooper, C., \& Barling, J. (Eds.). (2008). The Sage handbook of organizational behavior: Micro approaches. Retrieved from http://webuser.bus.umich.edu/Spreitzer/ Empowerment\%20and\%20self-management\%20ob\%20handbook\%20final.pdf Wiens, S., Babenko-Mould, Y., \& Iwasiw, C. (2014). Clinical instructors' perceptions of structural and psychological empowerment in academic nursing environment. Journal of Nursing Education, 53, 265-270. doi:10.3928/01484834-20140421-01 


\section{PART TWO \\ MANUSCRIPT}

In Africa, thousands of nurses and midwives provide health care and education, and are the most available and widely dispersed health care workers in the continent (Klopper \& Uys, 2013). Since CIs in Rwanda are responsible for the preparation of future nurses in this country, it is important to understand how CIs' perceptions of the practice environment influence their ability to engage in their role, a role that impact students' professional development. If nurses perceive themselves as empowered in their jobs, they will be more confident in their skills and knowledge, be more engaged in their role, and experience increased job satisfaction (Ahmad \& Oranye, 2010; Wang \& Liu, 2013). Effective clinical teaching or instruction demands that CIs guide, support, and facilitate student learning to gain vital knowledge, skills and practice values necessary for future practice as health care professionals. In the practice environment, instructors who role model empowering behaviors will better equip nursing students for professional practice on graduation (Babenko-Mould, Iwasiw, Andrusyszyn, Laschinger, \& Weston, 2012). As such, the CI role involves organizing and making available suitable activities that enhance students' clinical experiences (Gaberson \& Oermann, 2010).

Although there has been immense growth and advancement in nursing and midwifery in Rwanda, few of these developments have been described in the literature and there are limited written resources that describe the history and experiences of these health professionals (Mukamana, 2013). Given the importance of the CIs' role in students' professional development, it seems appropriate to conduct research to gain an understanding of CIs' experiences for teaching in the practice environment. Therefore, the purpose of this study was to explore the ways in which nursing clinical instructors in Rwanda described their experiences of structural (SE) and psychological empowerment (PE).

In 2011, a study was conducted in Rwanda where 21 CIs were interviewed prior to completing educational modules aimed to support them in their teaching role. Questions focused on gaining an understanding of their knowledge of practice-based teaching, and perceptions of their roles and responsibilities as facilitators of students' learning. Guided by Kanter's (1993) theory of structural power in organizations (SE) and Spreitzer's (1995) theory of psychological empowerment (PE), a secondary analysis of the interview data collected in the original study was 
conducted to gain an understanding of the CIs' experiences of empowerment related to their practice teaching role.

\section{Rwanda}

Rwanda is a country of a thousand hills, located in Sub-Saharan Central Africa in the Great Lakes region (Mukamana, 2013). The population for 2014 is estimated at 12.2 million, and increase from 11.8 million in 2013 (The World Bank, 2013). Rwanda is primarily an agricultural country with over $80 \%$ of the population living in rural settings. The capital of Rwanda is Kigali. Despite the period of civil war, Rwanda's economy is growing steadily due to community-driven initiatives that are responding to the needs of the population (Kloppers \& Uys, 2013). The greatest contributor to the country's gross domestic product is the service sector, with education, health, and public administration providing the strongest growth. This is largely due to the increasing funds from international donors and government fiscal policies. Statistics for 2011 reported approximately 700 physicians, 8000 nurses, and 300 midwives providing care for over 11 million people (Ministry of Health of the Republic of Rwanda (MOH), 2011). Rwanda falls below the minimum level of the World Health Organization's recommended health care providers per 1,000 people (WHO, 2006). The Ministry of Health $(\mathrm{MOH})$ is responsible for the health care system in Rwanda and is committed to improve and provide quality health resources for the population (Kloppers \& Uys).

There are three levels of nursing education to prepare nurses for the provision of patient care. Nurses practicing at district hospitals or in management positions at health clinics or hospitals generally have an A1 (diploma) or A0 (degree) designation with three or four years of post-secondary education. A2 nurses have completed a high-school diploma with some basic training in first aid (Anatole et al., 2013). In 1996, the MOH created the Kigali Health Institute (KHI) where A2 nurses were upgraded to an advanced diploma (A1) in mental health nursing, general nursing, and midwifery. In 2002, KHI introduced a bachelor's degree in nursing and a master's level in critical-care nursing in 2009. In 2007, Rwanda's MOH, in collaboration with other educational-based stakeholders implemented a competency-based teaching approach to education in schools of nursing and midwifery in an effort to phase out the lower-level A2 programs. The ultimate goal was to create a nursing workforce with A1 and higher-level educational preparation (The Capacity Project, 2007; Harerimana \& de Beer, 2013). 
In the last 16 years, the Kigali Health Institute (KHI) has graduated over 3000 health care professionals including nurses and midwives (Kloppers \& Uys, 2013). The regional nursing and midwifery school programs have recently come under the administrative umbrella of the University of Rwanda. Nursing education is provided through either a 4-year degree program at the University or a 3-year diploma of nursing program in one of 5 regional schools. As the $\mathrm{MOH}$ continues to support upgrading nursing education in Rwanda, a greater number of nurses with A1 and A0 designation will be available to practice and teach as health care professionals in this country.

\section{Theoretical Framework}

\section{Overview of Kanter's Theory of Structural Power in Organizations}

Kanter's (1993) structural empowerment theory (SE) recognizes organizational factors such as information, opportunity, support, and resources that have a direct effect on individuals' organizational behaviours and attitudes, job satisfaction, self-efficacy for professional practice, and organizational commitment (Babenko-Mould, et al., 2012; Laschinger, Finegan, Shamain, \& Wilk, 2001; Pineau Stam, Laschinger, Regan, \& Wong, 2013; Yang, Liu, Huang \& Zhy, 2013). Kanter (1993) defines power as the ability to activate resources to achieve organizational goals. Formal power comes from jobs that are recognized and serve to meet key organizational goals. Informal power is experienced with the development of relationships and connections with fellow employees within the organization. Both formal and informal systems of an organization can influence employee attitudes and behaviours. Information corresponds to knowledge required to make organizational decisions and carry out work related skills that align with organizational goals. Opportunity refers to expectations and hope for future prospects for mobility and growth within an organization. Support comes from superiors through feedback about performance and direction for making work related decisions. Resources include materials, finances and rewards needed to complete the job successfully (Kanter). Access to these structural components can empower employees to effectively implement practice goals and engage in positive ways that supports organizational outcomes (Smith, Leask Capitulo, Quinn Griffin, \& Fitzpatrick, 2012).

\section{Overview of Spreitzer's Theory of Psychological Empowerment}

Spreitzer (1995) defines PE as a motivational construct and refers to how people experience their work, specifically focusing on personal beliefs related to their role within an 
organization. The psychological perspective of empowerment includes four dimensions: meaning, competence, self-determination, and impact specific to the work environment. Meaning refers to how the needs of an individual's work role fit with their personal beliefs, values and behaviours. Competence relates to an individual's belief in their capability to perform job activities with skill. Self-determination refers to one's feeling of choice related to initiating decisions and regulating work behaviours. Impact comes from the sense of influence one perceives to have within the work environment for operating outcomes. PE is the sum of these dimensions and reflects a person's wish and ability to shape his or her work role (Spreitzer).

According to Spreitzer (2007), to have a complete understanding of empowerment in the workplace, integration of both structural and psychological empowerment perspectives is needed. This combines both the organizationally focused SE and individually centered PE. The working conditions within an organization can be described by the presence or absence of empowering structural conditions. To promote positive change within organizations, Spreitzer (1995) argues that organizations need to gain a better understanding of how SE can assist in building employees' PE and conversely how positive attitudes and behaviors characterized by PE can promote the development of SE. Therefore, to gain a comprehensive understanding of the experiences of the CIs in Rwanda, both theories were used to frame this study.

\section{Review of Literature}

\section{Search Methods}

A literature review was conducted to access electronic articles of research-based literature regarding (a) structural and psychological empowerment in nursing; (b) structural and psychological empowerment in nursing education; and (c) clinical instructors' roles in practice with students. Databases such as Cumulated Index to Nursing and Allied Health Literature (CINAHL), PubMed, Proquest Education Journals, Proquest Nursing and Allied Health Source, Google Scholar, MedLine OVID, and Scopus were searched from 2000 to 2014. Key words such as clinical instructors, clinical educators, clinical instructors' role, nursing education, structural empowerment, and psychological empowerment were used to guide the search. The key words were used individually, as well as in combination with each other. The literature review for this study specifically focused on recent research studies on Kanter's (1993) and Spreitzer's (1995) theories related to clinical instructors and nursing education. The following 
literature review section is organized under the following topic headings: the role of CIs, structural empowerment and the nursing literature, psychological empowerment and the nursing literature, and expanded empowerment model and the nursing literature.

\section{Role of Clinical Instructors}

The Canadian Association of Schools of Nursing (CASN) (2005) Position Statement for Clinical/Practice Nursing Education outlines the vital role CIs play in preparing students for the nursing profession. The CI facilitates students' learning and preparation to work in changing health care environments which are being faced with complex health care delivery issues (i.e., increased cost of care, safety, and quality of care) through fostering the development of critical thinking skills, problem-solving and clinical decision-making abilities, professional skills and competencies, and practice behaviours and attitudes (Brancato, 2007; CASN, 2012; Donaldson \& Carter, 2005; Paton, 2007; Price, 2004).

In Jordan, 156 senior nursing students identified a number of motivating behaviours demonstrated by CIs that enhanced the teaching role including, showing genuine interest in patients, and supporting student learning by being a knowledgeable and a resourceful person (Hayajneh, 2011). The author proposed that effective clinical instruction could be promoted by providing clinical faculty with useful educational tools such as a faculty manual with teaching tips and organizational guides (Hayajneh, 2011). The CIs' knowledge, abilities and personal attributes combined with professional education all contribute to expertise in the teaching role (Higgs \& McAllister, 2005). This is crucial for the future development of the nursing profession.

Dahlke, Baumbusch, Affleck, and Kwon (2012) conducted a literature review to gain an understanding of CIs perceptions of their role and identify factors that affect their ability to enact this teaching function. Analysis of 15 articles published between 2000 and 2011 identified four primary topics including characteristics of the role, characteristics of effective clinical teaching, influence of the clinical context on the role, and influence of the academic context on the role. Many of the CIs surveyed in these studies felt they frequently relied on personal and clinical experiences to guide their teaching, rather than formal education. Given the importance of clinical teachers, it is relevant to consider CIs' experiences within the practice teaching environment to understand how to strengthen their teaching role, and by extension support the development of confident, enabled nursing professionals. 


\section{Structural Empowerment and the Nursing Literature}

A search for recent nursing studies of empowerment showed an emphasis on SE (Kanter, 1993). For example Hauck, Quinn Griffin, and Joyce (2011) surveyed 98 nurses working in five critical care units in the northeastern United States (US) to examine the relationship between critical care nurses' perceived SE and anticipated turnover. Participants felt they were moderately empowered and more committed to their organizations thereby increasing intent to stay in their jobs. In another study, Hebenstreit (2013) surveyed 221 nursing educators teaching in baccalaureate nursing programs in the US where they examined perceived SE and innovative behaviour. Results demonstrated a strong link between the two factors, identifying informal power as a key component. The author suggested that support from colleagues may enhance one's ability to initiate change and adapt to new situations, and proposed that increased perceptions of empowerment for nurse educators would boost their ability to face and manage the challenges of the teaching role (Hebenstreit). In the nursing education context, BabenkoMould et al. (2012) used Kanter's (1993) SE theory, the empowerment process by Conger and Kunungo (1988), and Bandura's (1986) self-efficacy theory to assess the effects of the clinical practice environment on clinical teacher and nursing student outcomes. The participants included 352 senior year nursing students and 64 clinical teachers in acute care practice teaching environments from seven nursing education programs in Ontario. CIs felt they were structurally empowered and used empowering teaching behaviours. Clinical instructors' use of empowering behaviours enhanced students' perceptions of SE and confidence for professional practice. In nursing education, building students' confidence can help them recognize the importance of their contribution in the clinical practice area, potentially increasing commitment to the nursing profession. Therefore it is important to create environments that support teaching and learning by empowering clinical instructors in both the academic and practice settings.

\section{Psychological Empowerment and the Nursing Literature}

Several studies show support for Spreitzer's (1995) psychological empowerment (PE) theory (Chung \& Kowalski, 2012; Johnson, 2009; Wang \& Liu, 2013). For example, results of a study conducted by Chung and Kowalski who surveyed 959 full time nursing faculty in US nursing programs, demonstrated a positive link between mentoring quality, PE, and job satisfaction. Mentoring can foster positive coping strategies, provide social support and increase competence in practice, thereby psychologically empowering nursing faculty. In another study, 
Johnson (2009) surveyed 407 nursing faculty in 70 associate degree programs (AD) in the southwestern US. A positive association between organizational culture and faculty PE was found. The values, assumptions, expectations, and beliefs of a group or organization are factors that contribute to organizational culture. Wang and Liu (2013) found that professional practice environments and PE positively influenced work engagement of 300 clinical nurses in two local hospital environments in Tianjin, China. Patient safety outcomes and quality of nurses' work life are factors that contribute to professional practice environments. Generally, authors suggested that psychologically empowered nurses are more confident in their skills, find meaning in their jobs and work autonomously.

\section{Expanded Empowerment Model and the Nursing Literature}

Testing an expanded model of Kanter's (1993) SE theory, Laschinger et al. (2001) conducted a study with 404 staff nurses from urban tertiary care hospitals in Ontario. Results demonstrated a link between empowerment and job strain. SE led to increased levels of PE thereby affecting the degree of job strain experienced, demonstrating how both organizational and psychological components can positively affect employee outcomes.

With a focus on ways to promote retention of staff in the US, Baker, Fitzpatrick, and Griffin (2011) surveyed 139 full-time associate degree nurse educators (ADN) employed at 74 community colleges in California to examine the relationship between empowerment and job satisfaction levels. The ADNs perceived moderate levels of both SE and PE, which correlated with fulfillment in work performed and overall job satisfaction. The authors recommended professional development and mentoring to support the ADNs in their role.

Also focusing on nursing education, Wiens, Babenko-Mould, and Iwasiw (2014) conducted a qualitative study to gain an understanding of nursing faculty perceptions of SE and $\mathrm{PE}$ in academic nursing environments. Eight part-time nursing faculty members from two nursing schools in Ontario identified organizational support and confidence in their role as key priorities to enhance SE and PE in the academic environment. Recommendations included increasing CIs' support in the academic setting and promoting connections among faculty to foster the development and retention of nursing faculty. It is evident that the use of the expanded $\mathrm{SE}$ and PE framework has been supported in research on empowerment in nursing education. 


\section{Summary of the Reviewed Literature}

In summary, a number of studies have shown support for Kanter's (1993) SE and Spreitzer's (1995) PE theories (Babenko Mould et al., 2012; Baker, 2011; Chung \& Kowalski, 2012; Hebenstreit, 2013; Hauck et al., 2011; Laschinger et al., 2001; Wang \& Lui, 2013; Wiens et al., 2014) and highlighted the positive effects (job satisfaction, job commitment, innovative behaviour, student confidence, reduced job strain and work engagement) of empowering nurses and nursing faculty. Similar to this study, Wiens et al's (2014) descriptive qualitative research highlighted the importance of empowering CIs in the academic environment. They suggested further research is warranted to gain an understanding of CIs experiences of empowerment since key outcomes of CI retention, job satisfaction, and student achievement are at stake.

In Rwanda, no studies have been completed that explore the CIs' experiences of SE and PE. Using Kanter's (1993) and Spreitzer's (1995) theories to frame the current work, a secondary analysis of the data will shed light on the ways in which clinical instructors experience SE and PE components of empowerment as they engage in the role as facilitators of students' learning in Rwanda.

\section{Research Question}

One overarching research question was asked of the data. In what ways do nursing clinical instructors in Rwanda describe their experiences of structural (opportunity, information, support, resources, formal, and informal power) and psychological (meaning, competence, selfdetermination, and impact) empowerment?

\section{Methodology}

\section{Qualitative Descriptive}

A qualitative descriptive methodology based on a naturalistic inquiry approach was used to guide this secondary analysis of the interviews conducted with CIs in Rwanda. Qualitative descriptive studies provide a description of a phenomenon, may begin with a theory of the target phenomenon, and are interpretive in nature whereby analysis and interpretation of findings remain close to the data (Sandelowski, 2000, 2010). Naturalistic inquiry aligns with the philosophy and art of nursing that strives to understand how individuals create meaning in their lives and how they interact with others and their environment (Lopez \& Willis, 2004; van Manen, 1997). Qualitative research studies are knowledge building and encourage the researcher to seek new perspectives, make recommendations for change, and explore new areas of research. 


\section{Qualitative Description - Study Design and Method}

A qualitative descriptive study design using the constructs of Kanter's (1993) structural and Spreitzer's (1995) psychological empowerment theories were used as theoretical frameworks to explore CIs' experiences of empowerment in the practice environment. As outlined by Crabtree and Miller (1999) and Miles and Huberman (1994), a researcher can create an a priori template based on theoretical perspectives to organize interview data and make further interpretations. Inquiry is not only based on a methodological framework, but also by the researcher's attitude towards the data created by the study. In qualitative descriptive inquiry, thematic analysis is often used whereby the researcher stays close to the words and language communicated by the participants (Sandelowski, 2000, 2010). The interview data was drawn from a study conducted in 2011, entitled Nursing Education Capacity Building in Rwanda: Nursing Clinical Instructor Education Modules. Study participants included a total of 21 clinical instructors, 11 female and 10 male, who provided clinical instruction for nursing students in acute care areas in Rwanda. The average age of the participants was 37, and the average number of years of clinical teaching experience was seven years. Eighteen CIs also taught in the classroom setting, 17 worked full-time and 4 part-time. Eight were diploma qualified and 13 had completed a bachelor of science in nursing degree, with 18 having had worked in the hospital where they provided clinical instruction. In this study, practice environments involved acute care hospital environments in Rwanda.

\section{Data Analysis}

To assist in the organization of transcribed interview data from the 21 participants, a management software tool (NVivo) was used. NVivo assists researchers to identify and examine patterns and relationships in their data (Polit \& Beck, 2008). Based on Kanter's (1993) and Spreitzer's (1995) theoretical components, data was analyzed for relationships, patterns and themes guided by an a priori template. Exploring and interpreting the data from the clinical instructor interviews will influence the development of knowledge required to improve practice experiences for both the CIs and by extension, students in the practice setting.

\section{Approaches for Creating Quality Research}

According to Morse, Barrett, Mayan, Olson, and Spiers (2002), verification strategies to ensure data validity and reliability include investigator responsiveness, methodological coherence, theoretical sampling and sampling adequacy, an active analytical stance, and 
saturation. When used appropriately, these strategies guide the researcher's direction and development of the study.

Throughout this study to ensure validity and reliability and be responsive, the researcher continuously reviewed data and explored alternative explanations as to why certain interview data fit and did not fit into the main concepts and themes, considering all the possibilities available and not trying to move all data into one conclusion. Methodological coherence was maintained by ensuring the research question aligned with the method, and data analysis. To ensure validity and authenticity, this study followed the qualitative descriptive methodological approach as outlined by Sandelowski $(2000,2010)$. In qualitative research, authenticity refers to the extent to which the researchers adequately show a range of different conclusions related to the interpretation and analysis of the research data (Polit \& Beck, 2008). The research question was 'In what ways do nursing clinical instructors in Rwanda describe their experiences of structural and psychological empowerment?' A qualitative descriptive study design using the constructs of Kanter's (1993) SE and Spreitzer's (1995) PE was used to explore the CIs experiences.

In qualitative descriptive inquiry, the researcher stays close to the words and language communicated by the participants (Sandelowski, 2000). To maintain validity and accurately document the CIs experiences, key quotes that represented the identified themes were selected. The researcher sought feedback from thesis advisors to clarify and add depth to the data analysis process. An active analytical stance was maintained through a comprehensive literature review, and the use of an intensively researched theory. Direction and feedback was regularly provided to the researcher from thesis advisors with expertise in nursing education and empowerment. The sample consisted of 21 CIs, which was sufficient to account for all aspects of the phenomenon with saturation of themes (Morse, 2002).

Based on Kanter's (1993) and Spreitzer's (1995) theoretical components, an a priori template was created to guide the secondary analysis process. Exploring and interpreting the data from the clinical instructor interviews will influence the development of knowledge required to improve practice experiences for both the CIs and by extension, students in the practice setting. 


\section{Findings and Interpretation}

Interviews were conducted in 2011 with 21 CIs to gain an understanding about their knowledge of clinical teaching, roles and responsibilities, and student evaluation in the practice setting in Rwanda. These interviews were conducted prior to the CIs completing three educational modules, originally developed and tested in a separate study (Andrusyszyn, et al., 2011). Secondary data analysis of the CIs' experiences was conducted using the SE and PE components of the corresponding theoretical frameworks. Frequently, data fit multiple components of both empowerment theories. The following section is organized with headings related to structural empowerment (formal and informal power, opportunity, information, support, and resources) and psychological empowerment (meaning, competence, selfdetermination, and impact).

\section{Findings Related to Structural Empowerment}

Formal power. According to Kanter (1993), increased formal power comes from roles that are visible, acknowledged, and essential to the goals of the organization. Within these roles, employees have the freedom and flexibility to decide how work is accomplished (BabenkoMould et al., 2012; Laschinger \& Finegan, 2005; Ledwell, Andrusyszyn, \& Iwasiw, 2006). Reference to formal power was limited to one CI who described the challenge of knowing what was expected of students in a clinical course. The lack of full-time status as a clinical instructor left this participant feeling inadequately informed of the practice course requirements, limiting ability to complete work requirements. As participants responded to interview questions, reference to organizational policies and practices related to formal power were not mentioned. Importantly, however, questions specifically focused on what role the organization played in supporting the CIs in their teaching position were not part of the original interviews.

Informal power. Informal power is fostered through positive relationships and alliances with people at multiple levels including superiors, peers, and subordinates inside and outside the organization (Kanter, 1993). Informal power was perceived by 20 CIs through descriptions of positive relationships with students, fellow CIs, patients, staff nurses, charge nurses, doctors, midwives and the academic institution thereby providing support for workload demands, managing conflict issues, providing student feedback, and translating theory into practice in the clinical environment. As one CI described his/her experience of managing teaching 
responsibilities, “Ask me if I [can] manage to help you, I will do; if it is beyond me, I will ask my colleagues."

All but two participants described conflict in the practice setting characterized by a lack of respect shown for patients by students, for students by patients, and for students by staff nurses. When dealing with conflict issues, six CIs described connections with staff, a supervisor, or the academic institution that provided support and assistance for conflict management. These results suggest that many CIs were attempting to manage these situations on their own. Many CIs also explained that it was a common occurrence for students to witness nursing practice in the practice setting that was not consistent with theory they had learned in the classroom. Seven CIs spoke of the positive collaborative steps that could be taken with students, staff nurses and the academic institution to solve this dilemma. Less than half of the participants used communication and interpersonal collaboration as a mechanism to overcome this challenge.

A number of participants also identified work related challenges that lead to a sense of limited informal power including language barriers, limited qualified staff nurses and poor interprofessional collaboration. As one CI stated, " This bullying...it may also come from the poor relationships between students and staff, or also poor relationship between the institution and the clinical setting."

Opportunity. Opportunity refers to employees' expectations and hope for future development and growth such as job promotions, ongoing expansion, and increased job skills and rewards (Kanter, 1993; Ledwell et al, 2006). Three CIs made reference to opportunities within the Rwandan academic organization about ongoing knowledge acquisition, training, and wishes for future development. Although the CIs did not specifically give examples of the opportunities available to them for development and movement within the organization, they clearly outlined wishes for future training and suggestions for advancement in their professional role.

Information. According to Kanter (1993), employees require knowledge and information to carry out their jobs, including information related to role expectations, teaching strategies and evaluation methods. In the current study, eight CIs underscored the importance of communication and access to organizational information specifically to course objectives that were created by the institution. The institution also played a major role in communicating course 
expectations, providing evaluation forms, and personal safety protocols to the CIs and students in both the lab and practice settings.

Eight participants shared experiences of limited information surrounding issues of inadequate job training, resolutions for incidents of conflict, and a lack of communication tools reducing their sense of empowerment to carry out roles and responsibilities as facilitators of student learning in the practice environment. One CI emphasized the need for the organization to provide access to information and training to reduce the incidence of conflict by saying "It happens too much [bullying and incivility], there has to be orientation to the system." Another participant explained that some practice environments did not provide best placements for students to achieve course objectives. It was important for the CI to know whether the practice environment was conducive to student learning.

Support. According to Kanter (1993), employees must have support from their peers and colleagues to be empowered in their jobs. Support can come in the form of performance feedback, collaborative relationships, and shared problem solving. The CIs experienced support through assistance and guidance provided by colleagues, clinical staff, students, supervisors, and administration to help carry out their roles and responsibilities, manage overwhelming workload, conflict issues, students' theory practice gap, and complete student evaluations. As one CIs described how he/she relied on colleagues to help manage an overwhelming workload, "You need to discuss with others, how they are coping, sometimes you get simple ideas."

Limited access to support was discussed by 18 participants. Many cited language barriers and poor collaboration with clinical staff. A need for support was clear, evidenced by participants recounted experiences of students being mentored by nurses who had limited professional training, and limited materials such as personal protection supplies to successfully carry out their roles and responsibilities. One CI described a conversation with a nurse director related to students' witnessing nursing practice that is not "consistent" with the theory they learned in school, "She [nurse director] said because of financial problems, we cannot have the same care plan like it is in theory...we have to adapt, we can't do anything."

Resources. As suggested by Kanter (1993) access to resources, whether monetary, material or human in nature, are needed for employees to complete a job, thereby increasing a sense of structural empowerment. All participants recounted experiences of accessing resources in the various teaching-learning environments. As one CI shared, "At school, we have this 
service of counseling and guidance when [a] student has a problem." The most frequently expressed resources were the available evaluation tools, from formal pre-determined checklists to feedback from the nursing staff in the practice setting.

While the majority of CIs described important resources that were available to them to carry out their roles and responsibilities, $17 \mathrm{CIs}$ also highlighted challenges in significant areas such as a need to increase practice teaching staff and qualified staff nurses, and access to much needed personal protection materials. One CI explained, "[The] main problem we meet in our hospital, there are no materials."

\section{Findings Related to Psychological Empowerment}

Meaning. Meaning refers to how the needs of an individual's work role fit with their personal beliefs, values and behaviours (Spreitzer, 1995). In this study, a total of $21 \mathrm{CIs}$ expressed a sense of meaning by describing what they valued and believed in. Most significant were role modeling, role responsibilities, evaluation, teamwork, collaborative communication, and facilitating student learning. When dealing with conflict issues, four CIs believed that communication, respect and individual evaluation could help facilitate conflict resolution. For the CIs, bridging students' theory-practice gap meant upholding the professional standards and role modeling professional practices for the students and for the staff in the practice setting. As one participant shared what it meant to be a CI, "Being a facilitator of students' learning means that you are being used as an agent of change, and an agent for learning."

In interviews from six participants, discrepancies and disconnect between personal beliefs and professional role requirements were identified. Some CIs felt unable to carry out their roles and responsibilities to the standards they wished. These latter outcomes were most frequently as a result of limited time, and overwhelming workload. Although the results were derived from a small number of participants, the issues they raised may also have been experienced by other CIs.

Competence. According to Spreitzer (1995), competence comes from a person's belief in his/her ability to complete job requirements with skill and empowers people to shape his or her work role. All interview participants expressed a sense of competency as they described the professional attributes they utilized while facilitating students' learning in the practice setting. Specifically, 16 interview participants felt competent in their ability to provide students with a link between what was taught in the classroom and skills lab, to practice in the practice setting 
through a number of approaches and strategies. One CI stated, "I have to role model certain behaviors... [this is] how I do my work as a professional."

As it was a major role for the CIs to ensure that the students practiced according to professional standards, inconsistencies in the practice setting limited their ability to carry out this role. The three main reasons given for these inconsistencies were poorly qualified mentoring nursing staff, communication problems, and poor collaboration between CIs and nursing staff which hampered the instructor's ability to advocate for the students and perform the job with competence. A sense of limited competency was also evident when discussing safety measures such as personal protection materials that the students were taught to use. The students followed the example of the staff nurses, and disregarded the instructions from the CI.

Self-determination. To have a sense of control within the work environment employees must feel that they have the choice and freedom to make decisions and regulate work behaviors (Spreitzer, 1995). A CI described his/her role, "[My] role is to be a leader, teacher, facilitator, and advocator for the students and clients." Self-determination was perceived as the CIs made use of their teaching knowledge, experience and abilities to determine the best approaches to facilitate student learning.

A sense of limited ability to control what was happening in the work environment was evident in interviews of 11 study participants. The reasons ranged from overwhelming workload and high instructor-student ratio, to language barriers, conflict issues and managing the theory practice gap. Many CIs comments reflected a sense of defeat at the inability to manage these challenges.

Impact. Impact comes from the sense of influence one perceives to have within the work environment for putting into operation business outcomes (Spreitzer, 1995). A sense of impact was perceived as the CIs described their professional roles and responsibilities. One participant described the impact they had on students learning, "I believe as a CI, you should be able to guide them [students] [to] be able to see where they will be in the future." Ensuring the safety of their students and patients was paramount; therefore, the CIs used a number of strategies to influence the students' choices for safe practices in the practice setting. The importance of initially forming a firm foundation in the skills lab practicing putting theory into action, was also stated by a number of CIs. Bullying and incivility was a challenge CIs faced in the practice setting. This was most likely due to the previously discussed differing levels of training and 
experience of the students and nursing staff. Impact was perceived when participants described ways in which they dealt with conflict and how they felt they influenced the outcomes of these troubling incidents.

While the majority of the CIs felt they had an impact on students' professional development, 17 felt limited in their ability to influence students' learning. The key challenges such as heavy workloads, conflict issues, lack of materials, unqualified nursing staff, language barriers and a lack of collaboration lead to a number of comments where a sense of limited impact was perceived. Feeling unable to complete job responsibilities limited the CIs' sense of ability to influence students' learning. In the practice environments, the CIs were met with a number of challenges including limited good practice placements, lack of materials, poor communication with staff and fellow CIs, strained collaborative relationships and incidents of bullying and incivility. These challenges limited the CIs ability to have an impact on the students' practice experiences, lessening the degree to which they felt they could influence the outcomes of the teaching program. As one CI summarized his/her feelings, "I think we can do better than we are doing right now."

\section{Summary of Findings}

The findings of this study reflect that CIs who participated in this study experienced both $\mathrm{SE}$ and PE empowerment components. The SE component of resources and the PE component of competence were identified by the CIs as key areas that supported and empowered them as facilitators of student learning. This was evident in the number and richness of data references from the greatest number of participants.

While support from colleagues, staff nurses and students to carry out teaching responsibilities in the practice setting was referenced by most participants, limited support was experienced by a number of instructors as they strived to support the students' application of theory to nursing practice in the learning environment. This was frequently due to the lack of qualified nursing staff in the practice areas to mentor the students. The majority of clinical instructors also expressed a sense of impact as they facilitated students' learning through their professional teaching practices and behaviors. However, a number of challenges included, heavy workloads, lack of qualified nursing staff, and language barriers within the practice setting limited impact for a number of clinical instructors in Rwanda. While these challenges limited 
the CIs ability to carry out their role, they generally felt that their teaching positions were vital to the development of students' knowledge and competence for future professional practice.

\section{Discussion}

The purpose of this study was to gain an understanding of nursing clinical instructors' experiences of structural and psychological empowerment related to their role in the practice teaching environment of Rwanda. Overall, the study findings provided support for the use of the expanded model by Laschinger et al. (2001) utilizing both Kanter's (1993) SE and Spreitzer's (1995) PE theories as explanatory frameworks. According to Spreitzer, a comprehensive understanding of empowerment in the workplace comes from considering both empowerment perspectives. In this study, the CIs shared experiences of clinical teaching that were positioned in both SE and PE empowerment components. For example, references of competence were frequently linked to the PE components of impact and meaning; and many CIs who described experiences of informal power also felt they had access to support and resources. Lethbridge, Andrusyszyn, Iwasiw, Laschinger, and Fernando (2011) also utilized both SE and PE empowerment theories to gain an understanding of nursing students' perceptions of empowerment in the learning environment and the possible affect on reflective thinking. Results of this literature review underscored the positive link between SE and PE in the classroomlearning environment and highlighted the importance of fostering empowerment in nursing education.

In this study, PE for the CIs in Rwanda stemmed from a sense of competence, meaning, impact, and self-determination they had for their teaching roles and responsibilities in the practice setting. While the SE components of informal power, access to resources, and support were also perceived by most study participants, limited formal power and opportunity diminished their sense of SE. This suggests there may be a need for administrators to create incentives to support and increase the CIs' SE.

The importance of support, employee incentives and opportunities within the workplace environment were highlighted in studies conducted by Hanson (2011) and Eta, Atanga, Atashili, \& D’Cruz (2011). For occupational therapy (OT) students in the US, opportunities for continued professional development, and the opportunity to shape the values and skills of future employees were incentives that motivated them to take on the role as a fieldwork educator. In three district hospitals of Cameroon, Central Africa, clinical nurse educators, (CNEs) identified a lack of 
opportunities to improve knowledge and skills, lack of preparation for clinical teaching, and insufficient working materials as the major challenges in the practice settings (Eta et al.). The authors highlighted the need for administration to provide employee incentives including basic working and teaching equipment, opportunities for ongoing training for nursing practice and teaching (Eta et al.). In the current study, a number of CIs also highlighted the importance of and need for opportunities to advance in their nursing education. As one CIs stated "We wish if Western Ontario can help us to continue [to] develop our training in degree, masters, $\mathrm{PhD}$, to help our students to know and have enough knowledge and skills."

Overall, the findings highlight the importance of developing nursing educational environments, both academic and clinical, with links to empowering components that enable nurse educators and instructors to accomplish their work (Baker er al., 2011; Babenko-Mould et al., 2012; Hebenstreit, 2012; Lethbridge et al., 2011; Mead, 2011; Wiens et al., 2014). For example, nursing faculty in baccalaureate programs in the US perceived a strong link between informal power and innovative behavior (Hebenstreit, 2012). In southwestern Ontario, a number of CIs teaching in academic environments were empowered through support received from coordinators and other academic faculty and confidence in the form of information sharing from faculty, opportunity for role development, and the freedom to effectively meet organizational goals (Wiens et al.).

In the current study, access to resources was perceived as the most important SE component by the instructors, based on the depth of the narratives and number of references to this theme in their interviews. Resources were identified as course materials such as evaluation forms and research resources for both faculty and students to help bridge theory learned in the classroom and skills lab to practice in the clinical environment. The CIs also relied heavily on resources of the human kind with encouragement and assistance from colleagues, students, and nursing staff to help complete evaluation requirements, manage workload stress, and resolve conflict issues in the clinical environment.

Results of an integrative literature review conducted by Lethbridge et al., (2011) highlighted the importance of educational resources in both the classroom and practice setting with opportunities for students to develop their reflective skills, including writing assignments, group interaction, and resources such as library and Web sites to enhance the development of students' reflective practice. Baker et al. (2011) recommended adding resources such as 
increased time to do paperwork, and time to accomplish job responsibilities to raise levels of empowerment and job satisfaction for associate degree nursing (ADN) educators teaching in public California community colleges in the US. In another study that focused on education and empowerment, Mead (2011) found that in private nursing colleges in Wisconsin, nurse educators had access to all organizational (opportunities, information, support, resources, formal and informal power) components in the graduate and undergraduate programs that ultimately empowered them in their teaching positions.

While these three studies support the current study findings of participants' frequent perceptions of access to resources, the context and identified resources differ significantly. All above studies are US based and resources differ from those identified by the CIs in Rwanda, which have been described. It is quite possible that the resources available to nursing faculty in the US, especially in private nursing colleges, are not available or available at a minimal level in Rwanda.

In this study, the frequently referenced access to resources contrasts with studies that examined structures that empowered nurse educators in Canadian and US workplaces (Baker, 2012; Hebenstreit, 2012; Sarmiento, Laschinger, \& Iwasiw, 2004). In these studies, resources were identified as time available to do paperwork, preparation time to meet role expectations, and additional time and support to manage heavy workloads related to high numbers of students. Study participants experienced moderate levels of SE linked to their meaning, competence, informal power and opportunity. Access to resources contributed the least to their sense of empowerment. It is possible that in these developed countries, resources may have been readily available, and therefore contributed less to the educators' empowerment as the other SE components.

Additional time to manage workload, an increase in clinical faculty, good clinical placement opportunities, and qualified nursing staff were identified as resources the CIs felt were needed in the practice setting in Rwanda. Time to manage workload supported the findings of studies conducted by Wiens et al., (2014) and Hebenstreit (2012) who highlighted CIs' and nurse educators' need for additional time to prepare to meet roles expectations. In this study, participants emphasized the need for more 'good' practice placements that would provide the 'best' learning environments for the students. The CIs reported that in many practice areas, students were mentored by nursing staff that lacked formal nursing education, making it difficult 
to achieve course objectives and expectations. Resources in the form of additional clinical teaching staff were also identified as needed resource to reduce the high student-instructor ratio.

The importance of providing mentoring opportunities and optimal clinical learning environments were explored in studies conducted by Anatole et al. (2013) and Crombie et al. (2013). In health centers (HC) of rural Rwanda, the nurse-focused Mentoring and Enhancing Supervision at Health Centers (MESH) program provided significant improvement in the nurses' ability to competently complete patient assessments and provide care in three practice areas (Anatole et al.). In England, results of a study conducted by Crombie et al. indicated that the quality of mentor support and practice experiences influenced nursing students' decision to complete their nursing programs.

The PE component of competence to carry out their role as a CI was experienced by all study participants and had the highest number of references for any empowerment component. The participants described with confidence teaching strategies they used in the clinical setting such as: role modeling practice behaviours, developing student-instructor relationships, planning, communication, and evaluation methods. Role-modeling, teaching abilities, and competence were also highlighted in studies by Heshmati-Nabavi and Vanaki (2010) and Johnson (2009). In the study conducted by Heshmati-Nabavi and Vanaki, Iranian faculty members believed competency was characterized by role modeling behaviors and the ability to use a solid knowledge base to link theory to practice. Johnson, who examined the relationship between the organizational culture of associate degree faculty and faculty empowerment of nursing faculty in the US, found that the participants, who perceived themselves as more competent in their teaching ability, were more empowered in their faculty role. For the CIs in Rwanda, references of competence were frequently linked to the PE components of impact and meaning. For example, the CIs perceived ability to carry out their teaching responsibilities was related to their beliefs on what it meant to facilitate student learning in the practice setting. With this confidence, the $\mathrm{CI}$ felt they possessed the qualities to have a positive lasting impact on student learning. As outlined by Spreitzer (1995), competence relates to one's belief in their ability to carry out job activities with skill adding to a sense of control within their work environment and competence ultimately contributes to psychological empowerment.

Current study findings reflect what was described by Baker et al. (2011), and Wiens et al., (2014), where nursing faculty from clinical and academic settings felt empowered in their 
workplaces, with competence identified as the most important PE component. In the current study, the CIs strong sense of confidence in their ability to carry out their teaching roles and responsibilities empowered them in their jobs in the practice setting.

The CIs also shared experiences that limited their confidence in the clinical setting. Students frequently observed nursing practice that was not consistent with theory learned in classroom, and poor communication and language barriers hindered collaborative practice. These challenges limited some CIs' beliefs in their ability to carry out their teaching responsibilities.

The theory-practice gap was explored from students' perspectives in a study conducted by Dadgaran, Parvizy, and Peyrovi (2012). Undergraduate nursing students in Tehran felt that instructors who were knowledgeable, self-confident, committed and who advocated for student opportunities to practice nursing skills, linked theory to practice. Patient and respectful nursing staff also impacted the students learning experience and overall theory to practice application.

In Rwanda, a number of CIs felt that for the students, observed practice not consistent with theory "happened all the time". It is unclear as to the reasons for this gap, but possible reasons include, lack of training of mentoring nursing staff and language barriers leading to communication challenges within a multicultural practice setting.

In Kuwait, Al-Enezi, Chowdhury, Shah, and Al-Otabi (2009) also found that immigrant nurses experienced challenges in adjusting to working in a new country, which lead to feelings of isolation in their multicultural work environment. In the practice environments of Rwanda, faculty and staff nurses also come from varying cultural backgrounds and languages, leading to challenges for communication and professional collaboration in the working environment.

A number of participants also expressed a sense of frustration related to the lack of personal protection materials available in the practice setting, limiting their ability to competently role model professional practice and provide a safe environment for their students. The importance of infection control (IC) resources was emphasized in a study conducted in South Africa, where drug-resistant tuberculosis (TB) is an occupational hazard for health-care workers (HCWs) (Zelnick, Gibbs, Loveday, \& Padayatchi, 2013). Health care professionals working in hospitals of KwaZulu Natal (KZN) identified lack of resources and inconsistent supplies that hindered IC. In the current study, the CIs also reported a lack of personal infection control supplies available for teaching faculty, staff and students in the practice settings. 
A sense of meaning was perceived as the CIs outlined the characteristics of an expert CI and what it meant to be responsible for providing students with an optimal learning experience in the practice setting. Meaning is derived from the value one places on one's work (Brancato, 2007; Spreitzer, 1995). As one participant described what it meant to carry out his or her role as a CI, "I have to role model behaviors that students have to follow...I do my work as a professional."

Role modeling professional practice behaviors and the importance of the clinical teaching role was discussed in studies completed by Klunkin et al. (2011) and Wiens et al., (2014). Nursing faculty in Thailand recognized that role modeling professional practice and excellence in clinical teaching was necessary for the development of the nursing students professional values (Klunkin et al.). CIs working in the academic setting in Ontario recognized that meaning came from role expectations that were aligned with their beliefs and they valued the positive impact they had on students' learning (Weins et al.). In Rwanda, the CIs also believed strongly in the importance of their teaching role and felt they positively impacted student learning outcomes, which added to their sense of competence and overall PE.

Meaning was limited for six interview participants because they felt they were unable to carry out their teaching responsibilities, as they believed they should in the practice area. This was due to limited time, overwhelming workload, and limited materials. These challenges were also evident in a study conducted by Naidoo and Mtshali (2007), who examined how 72 nurse educators in a South African college of nursing promoted reflective thinking in their teaching. While the majority of the nurse educators felt they utilized some reflective teaching strategies, the increased workload, large class size and insufficient time increased work strain, and made it difficult to carry out the teaching requirements. In Rwanda, the CIs held a high professional standard for themselves for carrying out their responsibilities, but a number of participants felt these standards did not fit with what they could manage given the above-mentioned challenges, potentially reducing psychological empowerment.

Along with competence and meaning, the PE component of impact was recognized in comments from the majority of interview participants. When the CIs had confidence in their teaching role, they also described how they influenced or had an impact on the students' nursing formation. As outlined by Spreitzer (1995), both impact and competence are linked to belief in one's ability to influence work outcomes. Knol and van Linge (2009) found that for nurses 
working in two general hospitals in the Netherlands, impact on their work environment was also a significant component of PE. The authors suggested that managers should seek to understand nurses' perceptions of their work environment and work roles, and support the creation of empowering working conditions focusing on SE, as this can influence PE and innovative behavior. In this study, the CIs were empowered with the ability to shape their teaching role to positively impact the students' professional development within the practice setting.

The CIs also influenced the students' practice experiences by trying to secure 'good' practice placements that would support the students' completion of course objectives. HartiganRogers, Cobbett, Amirault, and Muise-Davis (2007), and Al-Kandari, Vidal, and Thomas (2009) also underscored the importance positive clinical placements for nursing students. In the first study, participants highlighted the need for all involved in selecting and preparing nursing students' practice placements to collaborate and strive to secure areas that would promote learning and foster personal and professional student development. The authors recommended an assessment of clinical areas prior to placing students (Hartigan-Rogers et al.). Al-Kandari et al. also emphasized the need for more careful selection of clinical placement areas to complete course objectives, with a focus on positive learning environments, and collaboration between educational and practice settings. In the current study, the CIs ability to seek out positive learning experiences in the practice environment increased their sense of impact for student development and empowered them in their faculty role.

The importance of impact for the CIs in Rwanda may be partly due to the number of challenges and struggles they faced in the practice setting. The participants' comments clearly conveyed that they took their jobs very seriously and felt responsible for the students' growth and development in the practice environment in spite of or because of the challenges they faced. As one CI expressed, we need to "make sure they (students) are having the experience they should have" and another participant communicated his or her way to influence student learning was to "give opportunity to students to see the reality of clinical placements."

While the majority of the participants perceived a sense of impact for student learning, a number CIs also shared experiences of feeling frustrated and unable to complete job requirements limiting influence for student learning. The workplace challenges including demanding workload, lack of materials, limited good practice placements, and conflict issues lessened the impact the CIs felt they could have on the students' clinical education. As one CIs 
stated, "I think we can do better than we are doing now." Addressing some of the barriers in clinical teaching in Rwanda would clear the path for CIs to have a stronger impact on students' learning thereby increasing PE in the workplace.

The topic of conflict and unprofessional conduct within healthcare education environments has been examined by a number of researchers (Baingana et al., 2010; Clarke, Kane, Rajacich, \& Lafreniere, 2012; Hakojarvi, Salminen, \& Suhonen, 2014). Baingana et al. (2010) conducted a study with health sciences undergraduate students in Uganda, to explore their perceptions of experiences of professionalism. Study participants felt the formal course curriculum was inadequate to meet the standards for development of professional attitudes. Students felt that role models were essential to the development of positive professional practice behaviors. In Canada, undergraduate nursing students reported being bullied by clinical instructors and staff nurses who undermined their efforts in the clinical setting, and instilling impossible expectations (Clarke et al., 2012). Hakojarvi, Salminen, and Suhonen (2014) found that Finnish health care students had experienced verbal and non-verbal bullying resulting in physical and emotional health issues. Learning and professional development was negatively affected. In Rwanda, the CIs shared experiences of bullying within the practice setting not only impacted the instructors' ability to provide a positive learning experience for students, but compromised the collaborative working and mentoring relationships between students and staff.

With a sense of independence and self-determination, 19 CIs outlined how they personally created student specific teaching strategies and carried out their roles and responsibilities. Taking on a leadership role to determine the best approaches to facilitate learning in the practice setting and advocate for student learning experiences, added to the CIs' sense of competence in their ability to carry out their responsibilities and their ability to make a lasting impact on student learning. These findings may be similar to those found in a study conducted by Brancato (2007), where nursing faculty felt they had the ability and a sense of control for making choices and initiating actions within their work environments, empowering them in their teaching role in undergraduate nursing programs in the US. In another study, Stewart, McNulty, Quinn Griffin, and Fitzpatrick (2010) examined the relationship of PE and SE in practice for 74 nurse practitioners (NPs) working in the state of Connecticut. Study results showed a significant link between the two-empowerment processes with meaning and selfdetermination contributing the most to the participants' empowerment. For the CIs in Rwanda, a 
sense of self-determination came from the high regard they had for their professional responsibilities and the way they carried out their role as clinical instructors.

A number of participants perceived a sense of limited self-determination due to the significant identified challenges in the clinical area in Rwanda. The previously mentioned problems including language barriers, lack of trained staff nurses and a fear of losing clinical placement opportunities, hampered their ability to make work related decisions in the clinical setting.

To address the issue of a shortage of formally trained nurses and to better prepare nursing students for future practice, a competency-based education approach (CBE) was incorporated in five schools of nursing and midwifery in Rwanda in 2007 (Harerimana \& de Beer, 2013). The Capacity Project's (2008) objective is to create a workforce of higher-level professionals and phase out the lower level nursing programs in Rwanda. Recommendations to guarantee the success of this program and ultimately increase the number of higher level qualified nurses in Rwanda, included nurse educators' need for managerial support, in-service education, and seminars and workshops (Harerimana \& de Beer, 2013). In the current study, limited trained mentoring nursing staff affected the CIs ability to provide an optimal learning experience for the students reducing their sense of self-determination and empowerment in the workplace. The ongoing Capacity Project will increase the availability of trained nursing staff in the practice settings.

Formal power was limited to one CI describing her inability to be adequately informed and orientated to course expectations because of her lack of full time status. Highlighting the importance addressing orientation needs, Davidson and Rourke (2012) surveyed part time clinical nursing instructors (CNIs) from a Canadian university to measure the orientation learning needs for new part-time CNI faculty. Study participants identified orientation to curriculum content and objectives as a key learning need for CNI orientation. In this study, none of the interview participants communicated feelings of being valued in their jobs by the organization, or that their teaching positions were central to the organizations' purpose and goals. Although many CIs in the current study felt responsible for making sure that the students were placed in 'good' practice areas, interview data did not convey that they felt this responsibility added to their role flexibility or formal power, potentially reducing SE in the practice environment for faculty. 
The CIs in this study frequently described relationships with students, colleagues, and staff within the practice setting that were valued and provided support that positioned informal power as one of the key components of SE. Informal power often cross-referenced to the components of support and access to resources. For example, the CIs felt supported in their role through the positive collaborative relationships with colleagues and relied on these valuable resources. Interactions with peers helped the participants to problem solve and manage a number of challenges experienced in the practice setting. As outlined by Kanter (1993), alliances with people within and outside the organization builds informal power. These findings are contrary to the study conducted by Wiens et al., (2014), in which perceived informal power for CIs in the academic environment was limited, expressed by an inability to identify how their role fit within the program. The author suggested this might have been due to the physical separation of the CIs from academic faculty. In this study, the CIs experienced collaborative professional relationships, which strengthened informal pathways and positively influenced empowerment in the practice setting.

A number of participants identified challenges of language barriers, unqualified nursing staff, and poor communication, which limited participants' sense of informal power. Similar challenges were experienced by student nurses in South Africa who felt they had good interpersonal relationships with the clinic managers who had trained in the same nursing program, compared to experiences of poor communication with ward sisters who were 'single qualified' professional nurses (Mabuda, Potgieter, \& Alberts, 2008). For the CIs in this study, informal power was limited due to communication barriers and stressed relationships with mentoring staff, potentially reducing $\mathrm{PE}$ in the practice setting.

For 18 CIs in Rwanda, support for decision-making and problem solving came from colleagues, clinical staff, students, supervisors, and academic administrators. In a study conducted by Hauck et al., (2011), support also rated highly when exploring the relationship between SE and anticipated turnover in critical care nurses in the US. In this study, the CIs were empowered through support in the form of counseling for students experiencing conflict issues, staff nurses' assistance with student mentoring and evaluation, and interactions with colleagues.

Many CIs felt support was limited from the academic institution, especially as the CIs tried to link theory the students learned in the classroom to experiences in the practice setting. Support was also lacking as faculty dealt with incidents of bullying and strained relationships 
between the students and staff nurses. This was possibly due to the fact that many nurses who were responsible for mentoring and evaluating students lacked adequate training, while the students arriving in the practice setting had advanced knowledge and theory acquired in the classroom setting.

Access to opportunities was limited as a number of interview participants identified the need for further skills training, faculty orientation and wishes for additional and ongoing support for educational opportunities such as degree and graduate programs, and workshops to improve their knowledge and skills. The importance of providing staff with workplace opportunities was emphasized in a study conducted by Al-Enezi et al. (2007) who examined job satisfaction for nurses with multicultural backgrounds working in hospitals of Kuwait. A number of factors were identified that influenced job satisfaction including professional opportunities. In this study, the CIs also worked in a multicultural practice setting, and identified the need for opportunities for professional development, which could increase SE for teaching faculty.

Access to information was described by six CIs with references to library and Internet access, and evaluation forms created by the academic institution, and therefore contributed little to the participants' SE in the clinical setting. To be empowered in their jobs, not only do employees require access to knowledge and information to carry out their job responsibilities, but also an understanding of organizational policies and decisions (Kanter, 1993). The CIs in a study conducted by Wiens et al. (2014) also reported access to information was limited or not appropriately geared to their teaching needs and expectations. In this study, CIs felt that to be adequately prepared to carry out their teaching roles and responsibilities, information had to be available that clearly outlined and routinely updated course objectives and expectations.

\section{Implications and Recommendations}

\section{Implications}

The findings of this study have a number of implications for clinical instructors and nurse administrators. Given the support gained for Kanter's (1993) and Spreitzer's (1995) theories, it is important for health care professionals and teaching faculty to gain an understanding of the working conditions in the practice setting and introduce strategies to empower faculty in their jobs.

The study participants felt their teaching positions were vital to the development of students' knowledge base and competence for professional practice. But a number of significant 
challenges affected their ability to carry out their responsibilities, which had the potential to negatively affect the students' development in the practice setting. These included a lack of qualified nursing staff to mentor the students, conflict issues, language barriers among faculty and clinical staff, and students frequently observed practice not consistent to theory they had learned in the classroom.

A number of CIs also felt that the number of good practice placement areas was limited, and some feared 'loosing' access to placement spots likely due to conflict issues among staff, students and patients. The study participants appeared to be caught in the middle of trying to advocate for their students through providing the best practice learning experiences, and keeping the peace and maintaining positive collaborative relationships with students, staff and supervisors within the clinical environment.

None of the study participants gave examples of feeling valued in their jobs, or that teaching positions were seen by academic administrators as central to the purpose of the nursing program. While a few CIs expressed wishes for ongoing educational support, there was no mention of organizational opportunities for ongoing development of knowledge and skills.

This lack of ability to access and/or lack of effort in seeking out SE components may cause the CIs to practice in isolation, only seeking assistance when absolutely necessary and then seeking help only from colleagues. Limited direction from the academic administrators could lead to inconsistencies in teaching strategies and compromise the quality of clinical teaching. Without support from administration, the CIs could feel frustrated and discouraged, which ultimately could affect personal commitment to their jobs. If challenges are not addressed, the CIs could continue to have difficulty in accessing and maintaining good clinical placements. The CIs' focus on keeping the peace in the clinical setting, and being responsible for seeking out optimal clinical experiences for students could compromise their ability to engage in the teaching role.

The CIs' frequent references to conflict issues within the clinical setting is worrisome, as an environment of stress affects not only the CIs, but also the students and staff. CIs' need to help resolve issues of conflict reduces time available to teach and ability to carry out their responsibilities, and negatively affects job satisfaction. Students may become disillusioned with the nursing program and not complete their education in this field. Strained relationships 
between the students, CIs and nursing staff will affect the quality of the mentoring experience and staff may ultimately opt to withdraw their mentoring services.

\section{Recommendations}

To increase the CIs sense of empowerment, there is a need to strengthen collaboration between faculty, administration, and clinical staff. Input from CIs and nursing staff needs to be sought, and experiences shared especially surrounding challenges and communication barriers within the clinical setting. Such a recommendation has merit in regards to Rwanda where it is not uncommon for formal leaders to meet with 'front-line' health professionals to get a clear understanding of the issues and to discuss solutions. An example of such a process is evident even at a national level in Rwanda where a discussion forum called a Umushyikirano has been held since 2003 where leaders, including President Kagame, Cabinet and community members exchange ideas, share experiences, and pose questions (Umushyikirano Overview, 2014). If unable to attend the event in person, Rwandans are able to participate via telephone, SMS, Twitter, and Facebook and can also follow the debate live on television or radio (Umushyikirano Overview). Further, President Kagame of Rwanda frequently engages in outreach visits to numerous communities to discuss education, employment opportunities, healthcare, and infrastructure issues (The New Times Rwanda, 2014). This is an example of the transparent and participatory process that Rwandan citizens are encouraged to engage in to share ideas and problem solve together for an even stronger country. It is proposed that such practices can in fact carry over to the academic and practice-based health care context. For instance, in the nursing education context, it is recommended that administration, faculty, nursing staff, and students also meet and discuss work related issues. A committee could be created with representatives from each area that would meet on a regular basis to discuss role responsibilities and working conditions ultimately strengthening formal power and promoting networking in the practice setting.

The CIs shared a number of ideas for role enhancement including continued support for ongoing educational opportunities. These requests for ongoing education need to be brought to administration's attention. In-service training, workshops and seminars for faculty, staff and managers on interpersonal relationships and conflict resolution could foster positive communication in the practice setting (Harerimana, \& de Beer, 2013; Mabuda, et al., 2008). To help bridge language barriers, new faculty members emigrating from other countries could be 
linked with Rwandan speaking colleagues through the professional nurses association (Al-Enezi, et al., 2009). This link to a welcoming professional community could give new faculty an opportunity to socialize with other nurses and provide a sense of belonging within the new location, ultimately promoting recruitment and retention of staff.

There is also a need to have a greater understanding of what constitutes a good practice setting for students in Rwanda. Why are these placement opportunities limited, and is there a way to seek out more practice areas for the students to complete professional development? As suggested by Hartigan-Rogers et al. (2007) an assessment of clinical areas should be completed prior to selecting placements for the students. Al-Kandari et al. (2009) also recommended a need for more careful selection of clinical placement areas to complete course objectives with a focus on positive learning environments, and collaboration between educational and practice settings.

Improving communication and collaborative working relationships between administration, CIs, and staff could help all involved in nursing education to move towards creating strategies to solve the number of challenges being experienced in the clinical setting in Rwanda. A positive move in this direction would shift the CIs' focus from managing challenges to strengthening their teaching role, ultimately empowering them in their jobs as facilitators of student learning in the clinical setting.

\section{Recommendations for Further Research}

The use of SE and PE theories as an explanatory framework is recommended in future studies among CIs to explore their experiences of role engagement and effectiveness. In Rwanda, the CIs participated in interviews pre- and post-completion of educational modules. This study involved a secondary analysis of the pre-module use interviews from the original study. Another interesting study could explore experiences of SE and PE post-completing the educational modules for key components such as competence, and impact. Further studies could also involve implementing interventions such as conflict management strategies, additional educational and advancement opportunities, resources to reduce workload, and interventions to highlight faculty accomplishments, to examine key components such as formal power, opportunity, resources and support.

It would also be important to conduct additional research in other developing countries to gain a greater understanding of the how CIs, as key faculty members in practice-based education, engage in their role and ultimately impact students' professional development. It would also be 
relevant to examine how the clinical environment positively or negatively affects learning outcomes from the students' perspectives.

\section{Limitations}

The CIs were not specifically asked about opportunities or faculty support (formal power) or any interactions between administration/management and themselves. This was possibly the first opportunity the CIs had to share their experiences and voice their concerns regarding the number of challenges they faced in the practice environment. The study researcher did not travel to Rwanda or meet the study participants to complete member checking and clarify interpretations of data.

\section{Conclusion}

This is the first study known to the author that has examined the experiences of empowerment for CIs of Rwanda from an expanded theoretical perspective. The findings of the study provided support for the use of Kanter's (1993) SE and Spreitzer's (1995) PE theories to describe the experiences of CIs in the practice environment. The CIs who participated in this study experienced all empowerment components, which both enhanced and limited their teaching role in the clinical setting. PE for the CIs in Rwanda stemmed from a sense of competence, meaning, impact, and self-determination they had for their teaching roles and responsibilities in the clinical setting. Most study participants perceived access to the SE components of resources, and support, but limited formal power and opportunity diminished their sense of SE.

While the CIs expressed feelings of pride and an acute awareness of the responsibility for their teaching role, support, recognition and access to professional development opportunities would empower them in their faculty positions in the clinical setting. The number of challenges experienced by the study participants compromised their ability to more fully engage in their role and to focus on the students' professional growth and development. To increase CIs' role effectiveness, job satisfaction and commitment, it is recommended that academic administrators in Rwanda gain a further understanding of the benefits of empowering components in the workplace. 


\section{References}

Ahmad, N., \& Oranye, N. (2010). Empowerment, job satisfaction and organizational commitment: a comparative analysis of nurses working in Malaysia and England. Journal of Nursing Management, 18, 582-591. doi: 10.1111/j.1365-2834.2010.01093.x

Al-Enezi, N., Chowdhury, R., Shah, M., \& Al-Otabi, M. (2009). Job satisfaction of nurses with multicultural backgrounds: A questionnaire survey in Kuwait. Applied Nursing Research, 22, 94-100. doi: 10.1016/j.apnr.2007.05.005

Al-Kandari, F., Vidal, V., \& Thomas, D. (2009). Assessing clinical learning outcomes: A descriptive study of nursing students in Kuwait. Nursing and Health Sciences, 11, 252,262. Doi:10.111/j.1442-2018.2009.00444.x

Anatole, M., Magge, H., Redditt, V., Karamaga, A., Niyonzima, S., Drobac, P., Mukherjee, J., Ntaganira, J., Nyirazinyoye, L., \& Hirschhorn, L. (2013). Nurse mentorship to improve the quality of health care delivery in rural Rwanda. Nursing Outlook, 61, 137-144. http://dx.doi.org/10/1016/j.outlook.2012.10.003

Andrusyszyn, M. A., Iwasiw, C., Jones, S., Babenko-Mould, Y., Ferguson, K., Elliott, J., \& Anderson, L. (2011). Clinical Instructor Role Preparation-Development of Three Online Educational Modules. Retrieved from http://www.uwo.ca/nursing/ cirn/CIRNIntroduction.html

Babenko-Mould, Y., Iwasiw, C., Andrusyszyn, M. A., Laschinger, H. K. S., \&Weston, W. (2012). Effects of clinical practice environments on clinical teacher and nursing student outcomes. Journal of Nursing Education, 51, 217-225. doi: 10.3928/0148483420120323-06

Baingana, R, Nakasujja, N., Galukande, M., Omona, K., Mafigiri, D., \& Sewankambo, N. (2010). Learning health professionalism at Makerere University: An exploratory study amongst undergraduate students. BioMed Central Medical Education, 10, 1-10. Retrieved from http:// www.springer.com/education+\%26+language/journal/12909

Baker, S., Fitzpatrick, J., \& Griffin, M. (2011). Empowerment and job satisfaction in Associate degree nurse educators. Nursing Education Perspectives, 32, 234-240. doi: $10.5480 / 1536-5026-32.4 .234$

Bandura, A. (1986). Social foundations of thought and action. A social cognitive theory. Englewood Cliffs, NJ: Prentice-Hall, Inc. 
Brancato, V. (2007). Psychological empowerment and use of empowering teaching Behaviors among baccalaureate nursing faculty. Journal of Nursing Education, 46, 537544. Retrieved from http://www.healio.com/journals/jne

Canadian Association of Schools of Nursing (CASN) (2005). Position statement: Clinical/practice nursing education. Retrieved from http:/www.casn.ca/vm/ newvisualattachments/856/Media/ClinicalPracticeNursing.pdf

Canadian Association of Schools of Nursing (CASN) (2012). 2010-2011 Student and Faculty Survey Report. Retrieved from http://www.casn.ca/en/Surveys_112/ items/13.html

Chung, C., \& Kowalski, S. (2012). Job stress, mentoring, psychological empowerment, and job satisfaction among nursing faculty. Journal of Nursing Education, 51, 381-388. doi: 10.3928/01484834-10120509-03

Clarke, C., Kane, D., Rajacich, D., \& Lafreniere, K. (2012). Bullying in undergraduate clinical nursing education. Journal of Nursing Education, 51, 269-276. doi:10.3928/01484834-2012409-01

Conger, J., \& Kanungo, R. (1988). The empowerment process: Integrated theory and practice. Academy of Management Review, 13, 471-482. Retrieved from http://aom.org/amr/

Crabtree, B., \& Miller, W. (1999). "Using codes and code manuals: A template organizing style of interpretation.” In: Crabtree, B. \& Miller, W., Doing qualitative research in primary care: Multiple strategies ( $2^{\text {nd }}$ ed.). (pp. 163-177). Newbury Park, CA: Sage Publications.

Crombie, A., Brindley, J., Harris, D., Marks-Maran, D., \& Morris Thompson, T. (2013). Factors that enhance rates of completion: What makes students stay? Nurse Education Today, 33, 1282-1287. http://dx.doi.org/10.1016/j.nedt.2013.03.020

Dadgaran, I., Parvizy, S., \& Peyrovi, H. (2012). A global issue in nursing students' clinical learning: The theory practice gap. Procedia-Social and Behavioral Sciences, 47, 1713-1718. doi:10.1016/j.sbspro.2012.06.888

Dahlke, S., Baumbusch, J., Affleck, F., \& Kwon, J. (2012). The clinical instructor role in nursing education: A structured literature review. Journal of Nursing Education, 51, 692-696. doi:10.3928/01484834-20121022-01 
Davidson, K., \& Rourke, L. (2012). Surveying the orientation learning needs of clinical nursing instructors. International Journal of Nursing Education Scholarship, 9, 1-9. doi: 10.1515/1548-923X.2314

Donaldson, J., \& Carter, D. (2005). The value of role modeling: Perceptions of undergraduate and diploma nursing (adult) students. Nurse Education in Practice, 5, 353359. doi: 10.1016/j.nepr.2005.05.006.

Eta, V., Atanga, M., Atashili, J., \& D'Cruz, G. (2011). Nurses and challenges faced as clinical educators: A survey of a group of nurses in Cameroon. PanAfrican Medical Journal, 8, 28-32. Retrieved from http://www.ncbi.nlm.nih.gov/pmc/articles/ PMC3201592/pdf/pamj-8-28.pdf

Gaberson, K., \& Oermann, M. (2010). Clinical Teaching Strategies in Nursing, $3^{\text {rd }}$ ed. New York: Springer.

Hakojarvi, H., Salminen, L., \& Suhonen, R. (2014). Health care students personal experiences and coping with bullying in clinical training. Nurse Education Today, 34, 138-144. http://dx.doi.org/10.1016/j.nedt.2012.08.018

Hanson, D. (2011). The perspectives of fieldwork educators regarding level II fieldwork students. Occupational Therapy in Healthcare, 25, 164-177. doi:10.3109/07380577.2011.561420

Harerimana, A., \& de Beer, J. (2013). Nurse educators' utilization of different teaching strategies in a competency-based approach in Rwanda. Africa Journal of Nursing and Midwifery, 15, 29-41. Retrieved from http://www.relais.lib.uwo.ca:8080/ posttoweb/ servlet/DownloadDocument?8869845.pdf

Hartigan-Rogers, J., Cobbett, S., Amirault, M., \& Muise-Davis, M. (2007). Nursing graduates' perceptions of their undergraduate clinical placement. International Journal of Nursing Education Scholarship, 4, 1-12. Retrieved from http:// journals1.scholarsportal.info.proxy1.lib.uwo.ca/tmp/10542731185723443285.pdf

Hauck, A., Quinn Griffin, M., \& Joyce, J. (2011). Structural empowerment and anticipated turnover among critical care nurses. Journal of Nursing Management, 19, 269-276. doi: 10.1111/j.1365-2834.2011.01205.x

Hayajneh, F. (2011). Role model clinical instructor as perceived by Jordanian nursing students. Journal of Research in Nursing, 16, 23-32. doi: 10.1177/1744987110364326. 
Hebenstreit, J. (2012). Nurse educator perceptions of structural empowerment and innovative behaviour. Nursing Education Perspectives, 33, 297-301. Retrieved from http://search.proquest.com.proxy1.lib.uwo.ca/education/docview/ 1086347625/ fulltextPDF/13BDDE478E128191F80/1?accountid=15115

Heshmati-Nabavi, F., \& Vanaki, Z. (2010). Professional approach: The key feature of effective clinical educator in Iran. Nurse Education Today, 30, 163-168. doi: 10.1016/j.nedt.2009.07.

Higgs, J., \& McAllister, L. (2005). The lived experiences of clinical educators with implications for their preparation, support and professional development. Learning in Health and Social Care, 4, 156-171. doi: 10.1111/j.1473-6861.2005.00097.x

Johnson, B. (2009). Empowerment of nurse educators through organizational culture. Nursing Education Perspectives, 30, 8-13. Retrieved from http://search.proquest.com. proxy1.lib.uwo.ca/education/docview/236639298/ fulltextPDF/13BDDEEDEB8780983AC/4?accountid=15115

Kanter, R. (1993). Men and women of the corporation, $2^{\text {nd }}$ ed. New York: Basic Books. Klopper, H., \& Uys, L. (2013). The State of Nursing and Nursing Education in Africa A Country-by-Country Review. Sigma Theta Tau International Honor Society of Nursing. Retrieved from http://lib.myilibrary.com.proxy1.lib.uwo.ca/ProductDetail.aspx?id=494002 ISBN-13: 9781935476832

Klunklin, A., Sawasdisingha, P., Viseskul, N., Funashiman, N., Kameoka, T., Nomoto, Y., \& Nakayama, T. (2011). Role model behaviors of nursing faculty members in Thailand. Nursing and Health Sciences, 13, 84-87. doi: 10.1111/j.14422018.2011.00585.x

Knol, J., \& van Linge, R. (2009). Innovative behaviour: The effect of structural and psychological empowerment on nurses. Journal of Advanced Nursing 65, 359-370. doi: 10.1111/j.1365-2648.2008.04876.x

Laschinger, H. K. S., \& Finegan, J. (2005). Using empowerment to build trust and respect in the workplace: A strategy for addressing the nursing shortage. Nursing Economics, 23, 6-13. Retrieved from http://www.nursingeconomics.net/cgibin/WebObjects/NECJournal.woa 
Laschinger, H. K. S., Finegan, J., Shamain, J., \& Wilk, P. (2001). Impact of structural and psychological empowerment on job strain in nursing work settings: Expanding Kanter's Model. Journal of Nursing Administration, 31, 260, 272. Retrieved from http://journals.lww.com/jonajournal

Ledwell, E., Andrusyszyn, M. A., \& Iwasiw, C. (2006). Nursing students' empowerment in distance education: Testing Kanter's theory. Journal of Distance Education, 21, 78-95. Retrieved from http://www.ijede.ca/index.php/jde

Lethbridge, K., Andrusyszyn, M., Iwasiw, C., Laschinger, H. K. S., \& Fernando, R. (2011). Structural and psychological empowerment and reflective thinking: Is there a link? Journal of Nursing Education, 50, 636-645. doi: 10.3928/0148483420110817-02

Lopez, K., \& Willis, D. (2004). Descriptive versus interpretive phenomenology: Their contributions to nursing knowledge. Qualitative Health Research, 14, 726-735. doi: $10.1177 / 1049732304263638$

Mabuda, B., Potgieter, E., \& Alberts, U. (2008). Student nurses' experiences during clinical practice in the Limpopo province. Curationis, 31, 19-27. Retrieved from http://www.curationis.org.za/index.php/curationis/article/viewFile/901/838

Mead, R. (2008). Nurse educator empowerment. Master's Dissertation. Marian University School of Nursing, Fond du Lac Wisconsin USA. Retrieved from http://search.proquest.com.proxy1.lib.uwo.ca/nursing/docview/

Miles, M., \& Huberman, A. (1994). Qualitative data analysis: An expanded source-book ( $2^{\text {nd }}$ ed.) New Park, CA: Sage Publications

Morse, J., Barrett, M., Mayan, M., Olson, K., \& Spiers, J. (2002). Verification strategies for Establishing reliability and validity in qualitative research. International Journal of Qualitative Methods 1, 1-19. Retrieved from http://www.ualberta.ca/ ijqm/

Mukamana, D. (2013). The state of nursing and nursing education in Africa. Chapter 15-Rwanda. Sigma Theta Tau International. Retrieved from http://lib.myilibrary.com.proxy1.lib.uwo.ca/ProductDetail.aspx?id=494002 
Naidoo, M., \& Mtshall, NG. (2007). How nurse educators promote reflective thinking in a college of nursing in KwaZulu-Natal. Masters dissertation. Durban: University of KwaZulu-Natal, South Africa. Retrieved from http://researchspace.ukzn.ac.za/ xmlui/handle/10413/1518

Paton, B. (2007). Knowing within: Practice wisdom of clinical nurse educators. Journal of Nursing Education, 46, 488-495. Retrieved from

Pineau Stam, L., Laschinger, H. K. S., Regan, S. \& Wong, C. (2013). The influence of personal and workplace resources on new graduate nurses' job satisfaction. Journal of Nursing Management. doi: 10.1111/jonm.12113 [Epub ahead of print]

Polit, D., \& Beck, C. (2008). Nursing resesarch: generating and assessing evidence for nursing practice $\left(8^{\text {th }}\right.$ ed.). Philadelphia: Lippincott.

Price, B. (2004). Mentoring: the key to clinical learning. Nursing Standard, 18, 8-12. Sandelowski, M. (2000). Whatever happened to qualitative description? Research in Nursing and Health, 23, 334-340. doi: 10.1002/1098-240X(200008)

Sandelowski, M. (2010). What's in a name? Qualitative description revisited. Research in Nursing and Health, 33, 77-84. doi: 10.1002/nur.20362

Sarmiento, T., Laschinger, H. K. S., \& Iwasiw, C. (2004). Nurse educators' workplace empowerment, burnout, and job satisfaction: Testing Kanter's theory. Journal of Advanced Nursing 46, 134-143. doi: 10.1111/j.1365-2648.2003.02973.x

Smith, T., Leask Capitulo, K., Quinn Griffin, M., \& Fitzpatrick, J. (2012). Structural empowerment and anticipated turnover among behavioural health nurses. Journal of Nursing Management, 20, 679-684. doi: 10.1111/j.13652834.2012.01384.x

Spreitzer, G. (1995). Psychological empowerment in the workplace: Dimensions, measurement, and validation. Academy of Management Journal, 38, 1442-1465. Retrieved from http://webuser.bus.umich.edu/spreitze/PsychEmpowerment.pdf Spreitzer, G. (2007). Towards the integration of two perspectives: A review of socialstructural and psychological empowerment at work. For publication in Cooper, C., \& Barling, J. (Eds.). (2008). The Sage handbook of organizational behavior: Micro approaches. Retrieved from http://webuser.bus.umich.edu/Spreitzer/ Empowerment\%20and\%20self-management\%20ob\%20handbook\%20final.pdf. 
Stewart, J., McNulty, R., Quinn Griffin, M., \& Fitzpatrick, J. (2011). Psychological empowerment and structural empowerment among nurse practitioners. Journal of American Academy of Nurse Practitioners, 22, 27-34. doi: 10.1111/j.1745-75992009.00467.x

The Capacity Project in Rwanda (November, 2008). Planning, developing \& supporting the health workforce: Training future nurses and midwives in Rwanda. Retrieved from http://www.capacityproject.org/index.php?option=com_content\&task=view\&id=200\&Ite mid $=108$

The New Times Rwanda: Three Lessons from President Kagame's recent upcountry tour. (2014, July 16). Retrieved from http://www.newtimes.co.rw/news

The World Bank (2013). Rwanda | Data - The World Bank. Retrieved from http://data.worldbank.org/country/rwanda

van Manen, M. (1997). From meaning to method. Qualitative Health Research, 7, 345369. doi: $10.1177 / 104973239700700303$

Umushyikirano Overview. (2014). Retrieved from http://www.rwandapedia.rw/explore/ umushyikirano

Wang, S., \& Liu, Y. (2013). Impact of professional nursing practice environment and Psychological empowerment on nurses' work engagement: Test of structural equation modelling. Journal of Nursing Management. Sept. doi: 10.1111/jonm. 12124

Wiens, S., Babenko-Mould, Y., \& Iwasiw, C. (2014). Clinical instructors' perceptions of structural and psychological empowerment in academic nursing environment. Journal of Nursing Education, 53, 265-270. doi:10.3928/01484834-20140421-01

Ministry of Health of the Republic of Rwanda (MOH). Rwanda health statistics booklet 2011. (http://moh.gov.rw/english/wp-content/uploads/2012/05/MOH_Annual_booklet2011.pdf

World Health Organization (WHO) (2006). World Health report: Working together for health: World Health Organizations Retrieved from http://www.sho.int/shr/2006/en

Yang, J., Liu, Y., Huang, C., \& Zhu, L. (2013). Impact of empowerment on professional practice environments and organizational commitment among nurses: A structural equation approach. International Journal of Nursing Practice, 19, 44-55. Retrieved from http://onlinelibrary.wiley.com/journal/10.1111/(ISSN)1440-172X 
Zelnick, J., Gibbs, A., Loveday, M., Padayatchi, N., \& O’Donnell, M. (2013). Healthcare workers' perspectives on workplace safety, infection control, and drug-resistant tuberculosis in a high-burden HIV setting. Journal of Public Health Policy, 34, 388-402. Retrieved from http://www.palgrave-journals.com/jphp/index.html 


\section{PART THREE \\ IMPLICATIONS, RECOMMENDATIONS, AND CONCLUSION \\ Summary of Key Findings}

Clinical instructors are teachers who supervise nursing students in the practice settings, have both clinical and teaching skills, and play an important role in facilitating students' application of theory learned in the classroom to practice in the 'real' clinical area (Dahlke, Baukusch, Affleck, \& Kwon, 2012). In the current study, a secondary analysis was completed using data from interviews that were conducted with clinical instructors (CIs) in Rwanda in 2011. In the original study, participants were asked to share their knowledge of clinical teaching, and perceptions of their roles and responsibilities as facilitators of students' learning in the clinical setting. The responses expressed the pride and dedication they felt for their faculty positions. While they were motivated to provide the best learning experiences for their students, instructors experienced a number of challenges that ultimately compromised their ability to effectively engage in their professional role. The CIs of this study taught in practice environments that were located in acute care hospital settings in Rwanda.

The findings of this secondary analysis provided support for the use of Kanter's (1993) structural empowerment (SE) and Spreitzer's (1995) psychological empowerment (PE) theories to describe the experiences of CIs in the practice environment in Rwanda. The CIs in this study experienced all empowerment components. The key SE components were access to resources, support and informal power. PE for the CIs in Rwanda stemmed from a sense of competence, meaning, impact, and self-determination they had for their teaching roles and responsibilities in the clinical setting. Limited formal power and opportunity diminished their sense of SE. All components of SE and PE affected the CIs' ability to engage in their teaching role, ultimately impacting students' professional development. The number of references to these empowerment components and richness of the narratives shared by participants substantiated these results.

\section{Implications and Recommendations}

\section{Clinical Instructors}

Clinical instructors play a vital role in providing effective clinical teaching and role modeling quality nursing practices (Eta, Atanga, Atashill, \& D'Cruz, 2011; Hayajneh, 2011; Kameoka et al., 2013). Although the CIs in Rwanda took their roles and responsibilities very seriously and tried to seek out the best learning experiences for their students, challenges in the 
practice setting compromised the ability to engage in their role, potentially impacting the quality of clinical teaching, and students' development as future nurses. There is a need for the CIs and the Rwandan health care system to identify and gain an understanding of these challenges, and create possible solutions. Limited access to empowerment components may cause CIs to practice in isolation, only seeking assistance when absolutely necessary, and then seeking help only from colleagues. Without adequate support to manage the significant challenges, CIs could become frustrated, discouraged, and mentally and physically fatigued, ultimately affecting their ability to carry out their responsibilities. It is recommended that CIs increase their understanding of empowerment components and how these components can increase their ability to engage in their teaching role, ultimately impacting on student professional development.

CIs need to be kept up to date on nursing knowledge and teaching skills to adequately facilitate student learning. It is therefore recommended that they seek out opportunities for ongoing development and education and advocate for themselves by requesting workplace seminars and workshops. For CIs in this study, it may also be helpful for them to develop relationships outside the clinical setting through the Rwanda Nurses and Midwives Association (RNMA).

The CIs were responsible for selecting and securing a positive learning practice environment for the students that was often a challenge because of limited "good" practice placements. The implications of this challenging responsibility could increase CIs workload, job stress, and limit time and effort to be able to focus on teaching responsibilities. The implications of working in this less than an optimal learning environment where staff nurses who mentored students often lacked formal training, could increase CIs' work stress, decrease role effectiveness, and limit ability to impact students' learning experience. Incidents of conflict were also shared by a number of CIs, likely a result of a disproportionate level of nursing knowledge and skills between the CIs, students and mentoring staff. An implication of this for CIs in general is it could lead students to frequently observe practice not consistent with theory learned in the classroom. This theory practice gap would add to job stress and potential workload for the CIs who are ultimately responsible for the students' professional development. Also, poor learning outcomes for students could compromise the CIs' integrity as teachers.

While the CIs in this study relied on one another to help manage teaching responsibilities, it is recommended that a more formal plan for networking be established with scheduled regular 
meetings open to all clinical faculty to exchange experiences, views, and ideas for change. Issues of conflict also warrant groups of people working together towards identifying problems and sharing solutions thereby providing support and fostering employee empowerment.

In Rwanda a competency-based education (CBE) approach is utilized in the nursing schools (Harerimana \& de Beer, 2013). It is recommended that CIs take an active part in curriculum design to ensure adequate implementation of CBE in the clinical setting. The curriculum should also provide opportunities for discussion of personal values, respect for others, and the organizations' code of conduct policy and regulations. There is a need for CIs to role model professional behaviors, which can reduce incidents of conflict and provide a foundation of professionalism for nursing students in the practice setting (Baingana et al., 2010). Mutual guidelines for professional conduct and anti-bullying practices should direct all interactions between staff, CIs and students (Hakojarvi, Salminen, \& Suhonen, 2014). CIs, staff nurses, unit managers and students should collaboratively select learning opportunities and create clinical learning outcomes (Mabuda, Potgieter, \& Alberts, 2008). It is also recommended that CIs and nursing program co-coordinators work together to link students with staff nurses who will support and build students' confidence and promote professional socialization. This strategy will help students feel connected, visible and valued in the practice setting. These students may have more positive clinical experiences and feel more committed to stay in the nursing profession on graduation (Babenko-Mould et al., 2012).

If the significant workplace challenges were addressed and solutions explored, the CIs would have more time and energy to focus on their role as clinical instructors. Collaborative working relationships, adequate supplies, qualified staff, and support from administration could increase access to empowerment components for the CIs of Rwanda. This would ultimately provide opportunities for the CIs to be empowered in their teaching positions, thereby improving teaching outcomes (Eta et al., 2011).

\section{Administration}

In the current study, administrators in the academic setting provided information regarding course objectives and requirements, and guidelines for student evaluation. However, participants did not appear to have access to information surrounding administrative policies and teaching guidelines, or support through performance feedback, which restricted formal connections and limited participants' SE in the clinical setting. Limited direction from administration for 
teaching policies and guidelines could potentially affect quality and consistency of clinical teaching, ultimately influencing students' learning and formation as future nurses.

While some participants expressed wishes for future educational support, there was no mention of opportunities provided by administration for ongoing academic development. Limited support for advancement in knowledge and training could hinder CIs' ability to advance professionally and move within the organization, potentially affecting the organizations' ability to recruit and retain staff (Davies, Laschinger, \& Andrusyszyn, 2006; Hauck, Quinn Griffin, \& Joyce 2011). It is therefore recommended that opportunities for ongoing development, growth, and learning be provided to position faculty for career promotions thereby increasing job satisfaction and empowering CIs in their teaching positions (Al-Enezi et al., 2009, Laschinger, 2008).

The CIs did not express a sense of feeling valued in their jobs by the academic institution, or that the teaching positions were central to the purpose of the nursing program. It is therefore important for administration to understand that nurses who are aware of the terms and conditions of their jobs and feel appreciated are also more likely to be satisfied with their work positions (Al-Enezi, Chowdhury, Shah, \& Al-Otabi, 2009).

Administrators would benefit from gaining an understanding of the benefits of empowering structures, as empowered CIs who experience job satisfaction are more likely to be committed to their jobs and less likely to leave faculty positions (Baker, Fitzpatrick, \& Griffin, 2011). To increase access to structural components, administrators should initiate empowerment changes for CIs that open lines of communication, promote accomplishments, and highlight faculty value and relevance to the nursing program. It is recommended that regular meetings be scheduled with administrators, managers, and faculty that would provide opportunities to discuss concerns, seek support, and make suggestions for change. Also e-mail updates, website access, and informal lunch meetings, could provide access to information of organizational practice, policies and procedures. Overall empowerment (SE and PE) for CIs could be considerably improved if access to formal pathways was strengthened with performance feedback and job recognition from the academic organization (Ledwell, 2006). It is therefore recommended that administrators conduct regular employee performance evaluations (Davies, Wong, \& Laschinger, 2011). 
It is also important that nursing administrators recognize and act on challenges CIs experience in the practice setting. In the current study CIs experienced challenges such as students' experienced theory practice gap, limited resources, conflict issues, and limited quality practice placements.

Steps to remove students' theory-practice gap can be made by assessing learning conditions, making careful selection of clinical cases, and choosing hospitals that can facilitate student learning (Dadgaran et al., 2012). Administrators who do not initiate quality improvement methods that identify and rectify resource gaps and provide funding to stock sufficient supplies such as personal protection materials in the practice setting are putting faculty, students and staff at risk for occupational hazards and could be held accountable for workplace injuries and infections (Kotagal et al., 2009). It is therefore recommended that basic teaching and working supplies be accessible to CIs in the practice setting so they are able to demonstrate and teach skills and safety measures proficiently (Eta et al., 2011). Academic and clinical administrators must also address CIs' reported incidents of conflict by developing policies and procedures that address these issues within health care environments where nursing students complete their clinical education (Clarke, Kane, Rajacich, \& Lafreniere, 2012). Students should be introduced to topics of bullying and coping strategies for negative experiences through the nursing curriculum and a zero tolerance policy be incorporated and reporting procedures outlined (Hakojarivi et al., 2014). The curriculum should also provide opportunities for students to gain an understanding of professional behaviors that value respect, communication, a code of conduct, privacy, integrity and kindness (Baingana et al., 2010).

Administrators need to support CIs by working collaboratively to seek and secure clinical placements for students that provide positive learning experiences (Al-Kandar, Vidal, \& Thomas, 2009). From students' perspectives, positive learning experiences are not likely to be related to the physical appearance of the practice environment, but how valued and supported they feel by faculty and staff. It is therefore crucial that placements offer a supportive environment (Hartigan-Rogers, Cobbett, Amirault, \& Muise-Davis, 2007). A stronger partnership between CIs and administration is recommended to ensure that the level of supervision and assessment of student performance is consistent and opportunities to practice essential skills are guaranteed (Stayt \& Merriman, 2013). 
In this study, it was found that there was a need to improve interpersonal relationships in the practice setting, particularly between staff nurses, students and CIs. One of the key reasons for conflict issues was because many staff nurses lacked adequate training to take on the influential role of teaching and coaching nursing students. Trained mentors for staff nurses may be useful for improving professional practice, reinforce student training, and facilitate improvements in the practice setting such as application of theory to practice, quality of patient care, and patient, student, and staff infection control and safety (Anotole et al., 2013). It is recommended that opportunities and incentives for training and professional development such as short courses or modules that could be added towards a recognized diploma, certificate or degree be made available to staff nurses (Atefi, Abdullah, Wong, \& Mazlom, 2013).

It is crucial that health care organizations understand the integrative nature of structural and psychological empowerment and organizational outcomes. An organization that supports access to SE components in the work environment utilizes a positive strategy that contributes to employees' PE and ultimately leads to positive work behaviors and attitudes (Wagner et al, 2010). By listening to CIs concerns and challenges, administrators might readily take the first steps towards empowering faculty in the practice setting.

\section{Students}

Unqualified mentoring nursing staff, and students witnessing practice not consistent with theory learned in class, may cause students to adopt poor professional practice skills. If students are being evaluated by nurses who are not formally trained with knowledge of professional practice standards, students may be inappropriately assessed as competent. Suboptimal practice development may lead to unsafe practice, poor patient care, and students not competently ready to work (Stayt \& Merriman, 2013). Students may drop out of the nursing program or not enter the work force on graduation because of poor clinical learning experiences (Chuan \& Barnett, 2012; Crombie, Brindley, Harris, Marks-Maran, \& Morris Thompson, 2013; Milton-Wildey, Kenny, Parmenter, \& Hall, 2013).

The CIs shared experiences of limited supplies and equipment in the practice setting. Implications of shortages of equipment especially disposable gloves, poor role modeling by nurses for students, include compromised student safety and poor quality patient care. Poor infection control practices observed by the students can have a negative impact on learning and 
future practice (Al-Hussami \& Darawad, 2013; Gould \& Drey, 2013; Hinkin \& Cutter, 2014; Ward, 2010).

Students who are engaged in the learning process from an empowering perspective, have the potential to develop into nurse leaders and problem-solvers initiating quality care for patients (Babenko-Mould, Iwasiw, Andrusyszyn, Laschinger, \& Weston 2012). It is important that students seek opportunities for safe and supportive practice environments where they can practice new skills with structured supervision (Dadgaran, Parvizy, \& Peyrovi, 2012). If CIs are not empowered in their jobs, students can be deprived of the opportunity to replicate empowering behaviors in future practice.

\section{Recommendations for Further Research}

This is a foundational study in the context of CIs in Rwanda that warrants further exploration of what reality is for faculty working in the practice setting in this country. It is therefore important to conduct research to further explore the challenges, needs, and hopes for the future for this group of nursing professionals. The SE and PE explanatory framework would also be useful in exploring factors that enhance or diminish role effectiveness and job satisfaction among the general CI population. It would be important to further explore factors that affect professional capabilities, job satisfaction and job commitment of CIs working in multicultural clinical environments (Al-Enezi et al., 2009). Further studies could involve implementing interventions such as mentoring and education for staff nurses in acute hospital areas who serve as preceptors/coaches during clinical placements for nursing students (Anotole et al., 2013). In Rwanda, it is also important to gain a better understanding of what constitutes a good clinical placement and how can placement areas be improved. These questions may be answered by seeking out the experiences of students, staff nurses, and CIs working in practice settings. The significant issue of bullying and incivility witnessed in the clinical setting by a number of study participants would benefit from exploration. It may be relevant to gain an understanding of the meaning of professionalism and professional behaviors among students, faculty and staff and whether there is support from the academic organization to support this concept that may reduce conflict issues (Baingana et al., 2010; Calvert \& Muchira-Tirima, 2013). A study to explore nursing graduates' perceptions of their undergraduate clinical placement in Rwanda would provide relevant and useful information from students' perspectives. Further exploration is needed to gain a better understanding of the challenges faced by CIs not only in developed 
countries, but also in developing countries such as Rwanda where it is quite possible that access to empowerment components is limited or undiscovered.

\section{Conclusion}

This is the first study known to the author that has explored the experiences of empowerment for CIs in Rwanda. While the study participants experienced a number of issues in the clinical setting that challenged their ability to engage in the teaching role, many highlighted the significance of their teaching role, "(It) means that the student is the center of learning"; "We should be a role model of professionalism and a model of a person who cares"; and "(A) role is to be a leader...also a teacher, a facilitator and an advocator for students and clients". Results of this study provide an understanding of the CIs experiences that may increase awareness and reinforce the need to strengthen collaboration between administrators and CIs, initiate conflict resolution strategies, mentoring, orientation, and additional funding to support faculty in the clinical setting. As one CI summarized his or her overall perception of teaching effectiveness, "I think we can do better".

Research has shown that SE (Kanter, 1993) and PE (Spreitzer, 1995) can be linked to job commitment (Smith, Andrusyszyn, and Laschinger, 2010), decreased job stress and burnout (O'Brien, 2011), job satisfaction and staff retention (Baker et al., 2011). It is therefore relevant that the academic organization in Rwanda take the opportunity to gain an understanding of the importance of empowerment components, and the potential positive educational outcomes for faculty, students, nursing staff, and clients in the practice setting.

In the last 16 years, the University of Rwanda has graduated over 3000 health care professionals including nurses and midwives. The university has also made significant advances in upgrading the advanced diploma level to full bachelor's degree in a number of disciplines including nursing. Future plans include increasing the numbers and effectiveness of faculty through further training and research mentorship, and the creation of new programs to support professional development of practitioners (College of Medicine and Health Sciences [CMHS], 2013). The findings and interpretations of this study related to the perceptions of empowerment of CIs in Rwanda may assist administrators' understanding of the CI role and highlight factors that can build faculty empowerment ultimately enhancing the teaching role and student learning experiences in the practice setting. 


\section{References}

Al-Enezi, N., Chowdhury, R., Shah, M., \& Al-Otabi, M. (2009). Job satisfaction of nurses with multicultural backgrounds: A questionnaire survey in Kuwait. Applied Nursing Research, 22, 94-100. doi: 10.1016/j.apnr.2007.05.005

Al-Hussami, M., \& Darawad, M. (2013). Compliance of nursing students with infection prevention precautions: Effectiveness of a teaching program. American Journal of Infection Control, 41, 332-336. http://dx.doi.org/10.1016/j.ajic.2012.03.029

Al-Kandari, F., Vidal, V., \& Thomas, D. (2009). Assessing clinical learning outcomes: A descriptive study of nursing students in Kuwait. Nursing and Health Sciences, 11, 252,262. doi: 10.111/j/1442-2018.2009.00444x

Anatole, M., Magge, H., Redditt, V., Karamaga, A., Niyonzima, S., Drobac, P., Mukherjee, J., Ntaganira, J., Nyirazinyoye, L., \& Hirschhorn, L. (2013). Nurse mentorship to improve the quality of health care delivery in rural Rwanda. Nursing Outlook, 61, 137-144. http://dx.doi.org/10.1016/j.outlook.2012.10.003

Atefi, N., Lim Abdullah, K., Wong, L., \& Mazlom, R. (2013). Factors influencing job satisfaction among registered nurses: a questionnaire survey in Mashhad, Iran. Journal of Nursing Management, Article in Press. doi: 10.1111/jonm.12151

Babenko-Mould, Y., Iwasiw, C., Andrusyszyn, M. A, Laschinger, H. K. S., \&Weston, W. (2012). Effects of clinical practice environments on clinical teacher and nursing student outcomes. Journal of Nursing Education, 51, 217-225. doi: 10.3928/0148483420120323-06

Baingana, R, Nakasujja, N., Galukande, M., Omona, K., Mafigiri, D., \& Sewankambo, N. (2010). Learning health professionalism at Makerere University: an exploratory study amongst undergraduate students. BioMed Central Medical Education, 10, 1-10. Retrieved http://www.biomedcentral.com/bmcmededuc

Baker, S., Fitzpatrick, J., \& Griffin, M. Q. (2011). Empowerment and job satisfaction in associate degree nurse educators. Nursing Education Perspectives,32, 234-240. doi: $10.5480 / 1536-5026-32.4 .234$ 
Calvert, M., \& Muchira-Tirima, K. (2013). Making sense of professionalism and being professional in a Kenyan higher education context. Journal of Education for Teaching: International Research and Pedagogy, 39, 370-382. Retrieved from http://dx.doi.org/10/1080/02607476.2013.80215910/1080/02607476.2013.802159

Chuan, O., \& Barnett, T. (2012). Student, tutor and staff nurse perceptions of the clinical learning environment. Nurse Education in Practice, 12, 192-197. doi: 10.1016/j.nepr2012.01.003

Clarke, C., Kane, D., Rajacich, D., \& Lafreniere, K. (2012). Bullying in undergraduate clinical nursing education. Journal of Nursing Education, 51, 269-276. doi: 10.3928/01484834-20120409-01

College of Medicine and Health Sciences (CMHS)(2013). Kigali health institute: A response to Rwanda's health delivery challenges. Retrieved from http://www.khi.ac.rw/schools/nursing-scences/general-nursing/

Crombie, A., Brindley, J., Harris, D., Marks-Maran, D., \& Morris Thompson, T. (2013). Factors that enhance rates of completion: What makes students stay? Nurse Education Today, 33, 1282-1287. http://dx.doi.org.10.1016/j.nedt.2013.03.020

Dadgaran, I., Parvizy, S., \& Peyrovi, H. (2012). A global issue in nursing students' clinical learning: the theory practice gap. Procedia-Social and Behavioral Sciences, 47, 1713-1718. doi:10.1016/j.sbspro.2012.06.888

Dahlke, S., Baumbusch, J., Affleck, F., \& Kwon, J. (2012). The clinical instructor role in nursing education: A structured literature review. Journal of Nursing Education, 51, 692-696. doi: 10.3928/01484834-20121022-01

Davies, A., Wong, C., \& Laschinger, H. K. S. (2011). Nurses participation in personal knowledge transfer: The role of leader-member exchange (LMX) and structural empowerment. Journal of Nursing Management, 19, 632-643. doi: 10.111/j.13652834.2011.01269.x

Davies, M., Laschinger, H. K. S., \& Andrusyszyn, M. A. (2006). Clinical educators' empowerment, job tension, and job satisfaction: A test of Kanter's Theory. Journal of Nurses in Staff Development, 22, 78-86. Retrieved from http://ovidsp.tx.ovid.com.proxy1.lib.uwo.ca/sp 
Eta, V., Atanga, M., Atashili, J., \& D’Cruz, G. (2011). Nurses and challenges faced as clinical educators: A survey of a group of nurses in Cameroon. PanAfrican Medical Journal, 8, 28-32. Retrieved from http://www.ncbi.nlm.nih.gov/ pmc/articles/PMC3201592/pdf/pamj-8-28.pdf

Gould, D., \& Drey, N. (2013). Student nurses' experiences of infection prevention and control during clinical placements. American Journal of Infection Control, 41, 760-763. http://dx.doi.org/10.1016/j.ajic.2013.01.025

Hakojarvi, H., Salminen, L., \& Suhonen, R. (2014). Health care students personal experiences and coping with bullying in clinical training. Nurse Education Today, 34, 138-144. http://dx.doi.org/10.1016/j.nedt.2012.08.018

Harerimana, A., \& de Beer, J. (2013). Nurse educators' utilization of different teaching strategies in a competency-based approach in Rwanda. Africa Journal of Nursing and Midwifery, 15, 29-41. Retrieved from http://www.researchgate.net/journal/16825055_Africa_Journal_of_Nursing_and_Midwifery

Hartigan-Rogers, J., Cobbett, S., Amirault, M., \& Muise-Davis, M. (2007). Nursing graduates Perceptions of their undergraduate clinical placement. International Journal of Nursing Education Scholarship, 4, 1-12. Retrieved from http://www.degruyter.com/view/j/ijnes

Hauck, A., Quinn Griffin, M., \& Joyce, J. (2011). Structural empowerment and anticipated turnover among critical care nurses. Journal of Nursing Management, 19, 269-276. doi: 10111/j.1365-2834.2011.01205.x

Hayajneh, F. (2011). Role model clinical instructor as perceived by Jordanian nursing students. Journal of Research in Nursing, 16, 23-32. doi: 10.1177/ 1744987110364326.

Hinkin, J., \& Cutter, J. (2014). How do university education and clinical experience influence pre-registration nursing students' infection control practice? A descriptive, cross sectional survey. Nurse Education Today, 34, 196-201. http://dx.doi.org/10/1016/j/nedt.2013.09.005

Kanter, R. (1993). Men and women of the corporation, $2^{\text {nd }}$ ed. New York: Basic Books. 
Kameoka, T., Nakayama, T., Funashima, N., Miura, H., Yamashita, N., \& Gorzka, P. (2007). Development of instruments for cross-cultural research on role model behaviors of nursing faculty in the United States and Japan. Journal of Nursing Studies, 12, 1-7. Retrieved from http://hdl.handle.net/10755/147690, 2012/09/26).

Kotagal, M., Lee, P., Habiyakare, C., Dusabe, R., Kanama, P., Epino, H., Rich, M., \& Farmer, P. (2009). Improving quality in resource poor settings: observational study in rural Rwanda. British Medical Journal, 339, 1311-1313. doi: 10.111/j/1365-2834.2010.01093.x

Laschinger, H. K. S. (2008). Effects of empowerment on professional practice environments, work satisfaction, and patient care quality. Journal of Nursing Care Quality, 23, 322-330. doi: 10.1097/01.NCQ.0000318028.67910

Ledwell, E., Andrusyszyn, M.A., \& Iwasiw, C. (2006). Nursing students' empowerment in distance education: Testing Kanter's theory. Journal of Distance Education, 21, 78-95. Retrieved from http://search.proquest.com.proxy1.lib.uwo.ca/docview/214487170?accountid=15115

O’Brien, J. (2011). Relationships among structural empowerment, psychological empowerment, and burnout in registered nurses working in outpatient dialysis centers. Nephrology Nursing Journal, 38, 475-481. Retrieved from http://www.annanurse.org/nnj

Mabuda, B., Potgieter, E., \& Alberts, U. (2008). Student nurses' experiences during clinical practice in the Limpopo province. Curationis, 31, 19-27. Retrieved from http://www.curationis.org.za/index.php/curationis/article/viewFile/901/838

Milton-Wildey, K., Kenny, P., Parmenter, G., \& Hall, J. (2013). Educational preparation for clinical nursing: The satisfaction of students and new graduates from two Australian universities. Nurse Education Today, Retrieved from http://blog.apastyle.org/apastyle/2012/08/almost-published.html

Smith, L., Andrusyszyn, M., \& Laschinger, H. K. S. (2010). Effects of workplace incivility and empowerment on newly-graduated nurses' organizational commitment. Journal of Nursing Management, 18, 1004-1015. doi: 10.1111/j.1365-2834.2010.01165.x 
Spreitzer, G. (1995). Psychological empowerment in the workplace: Dimensions, measurement, and validation. Academy of Management Journal, 38, 1442-1465. Retrieved from http://webuser.bus.umich.edu/spreitze/PsychEmpowerment.pdf

Stayt, L., \& Merriman, C. (2013). A descriptive survey investigating pre-registration student nurses' perceptions of clinical skill development in clinical placements. Nurse Education Today, 33, 425-430. http://dx.doi.org/10.1016.j.nedt.2012.10.018

Wagner, J., Cummings, G., Smith, D., Olson, J., Anderson, L., \& Warren, S. (2010). The relationship between structural empowerment and psychological empowerment for nurses: A systematic review. Journal of Nursing Management, 18, 448-462. doi: 10.1111/j.1365-2834.2010.01088.x

Ward, D. (2010). Infection control in clinical placements: Experiences of nursing and Midwifery students. Journal of Advanced Nursing, 66, 1533-1542. doi: 10.1111/j.1365-2648.2010.05332.x 


\section{Appendix A}

Interview Questions

Re: Interviews conducted to gain an understand knowledge related to clinical teaching, roles and responsibilities of a clinical instructor, and evaluation of student performance.

Please tell me about...

1. What strategies do you feel that a clinical instructor could use to role model professional practice?

2. What behaviors or actions are associated with an expert clinical instructor?

3. What does being a facilitator of students' learning mean for you?

4. What strategies could a clinical instructor use to promote safety when students are working with patients?

5. What supportive actions could a clinical instructor take if he or she was feeling overwhelmed with work demand?

6. What do you believe are some of the roles and responsibilities of a clinical instructor?

7. What strategies could a clinical instructor use to deal with bullying or incivility?

8. How might a clinical instructor enhance the student-instructor professional relationship?

9. In what ways do you feel that the clinical instructors demonstrate that they view students as adult learners?

10. What are your thoughts about constructivist learning theory?

11. What learning strategies can a clinical instructor use to promote students' critical thinking?

12. What do you feel are effective questioning techniques? Why?

13. In what ways can a clinical instructor assist students to link theory to clinical practice?

14. What should a clinical instructor do if a student approaches them to say that they have observed nursing practice that is not "consistent" with the theory they learned in school?

15. What actions would you take to assist a student that was feeling very anxious in the practice setting and is fearful of approaching patients?

16. What is your opinion of formative feedback? 
17. What sources do you generally use to contribute to a student's evaluation?

18. What are the actions that you might take if you noticed that a student was not meeting the clinical course expectations?

19. What can the clinical instructor do to become familiar with what is expected of students in a clinical course?

20. What resources or tools do clinical instructors use to evaluate students clinical performance?

21. How often are students evaluated in their clinical practice? 


\section{Appendix B}

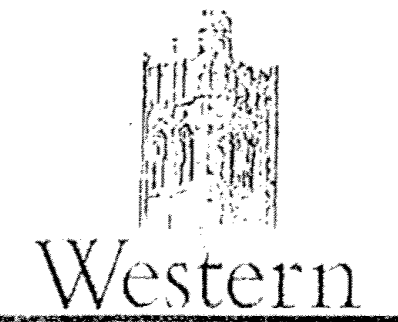

Principal Investigator: Dr. Y. Babenko-Mould

Review Number: $17524 \mathrm{E}$

Review Date: October 27,2010

\section{Office of Research Ethics}

The Unversity of Westem Ontario

Room 4180 Support Services Building, London, ON, Canada N6A 5C1

Telephone: (519)661-3036 Fax: (519) 850-2466 Email: ethics@uwo.ca

Website: Www uwo calresearch/ethics

\section{Use of Human Subjects - Ethics Approval Notice}

Protocol Tille: Nursing Education Capacity Bulding in Rwanda: Nursing chinical mstuctor Eductlonal Modules

Department and Institution: Nusing. Unversity of Westem Ontaro

Sponsor: Assoctation of Unversities and Colleges of Canada

Ethics Approval Date: November 16,2010 Expiry Date: December 31,2011

Documbnts Reviewed and Approved: UWO Protocol, Letter of Information to the Rector, Letter of htothation to lhe Dean. Letter of Intormation to the Clinical instructors, omait script.

Documents Received for Information:

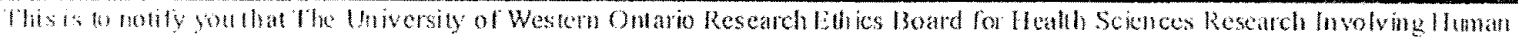

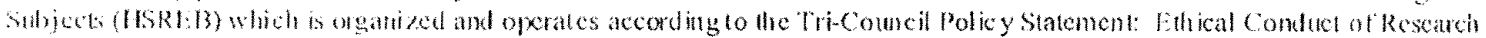

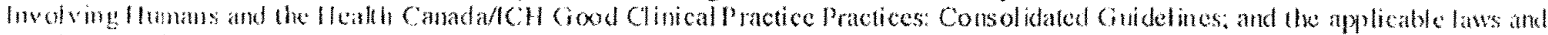

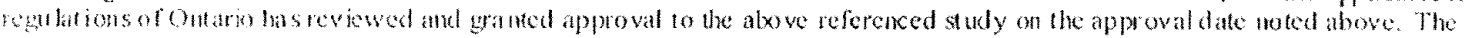
membersh of th is RTB ation complies with the membership requirements for REB's as defincd in Division 5 of the looxl and Drug Rezulations

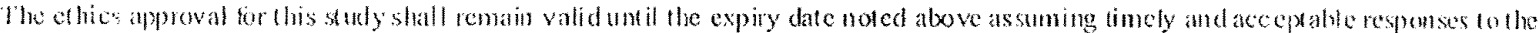

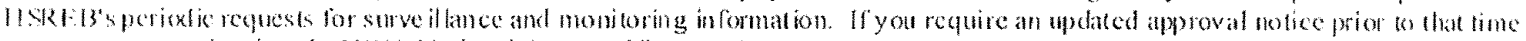
yon must reguest is using the (IWO Upalated Approval Request Form.

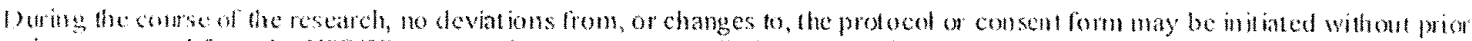

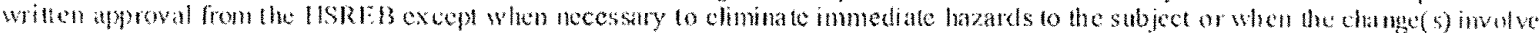

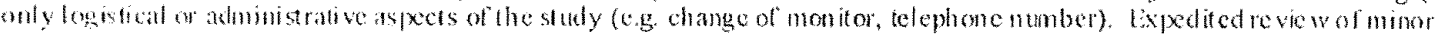
thanger in ongong studies will be considered. Subjects mest recive a copy of the signed information/consent doemmentation.

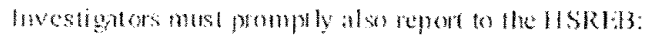

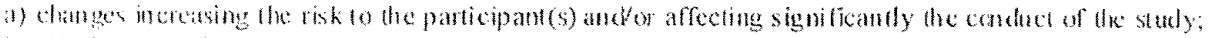

b) all atverse ant me xpected experiences or events that are both serious and unexpeted:

C) new thomation that may adwersely atfect the salety of the subjects or the conduct of the study.

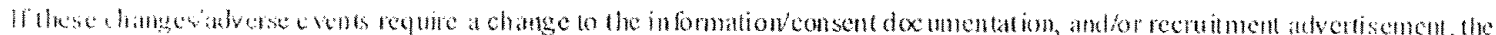

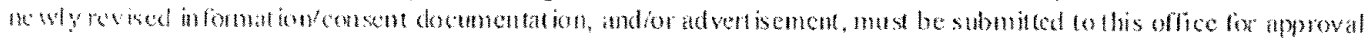

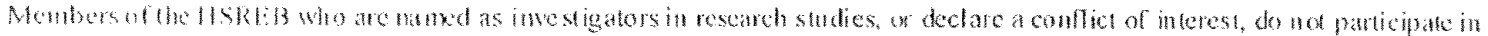

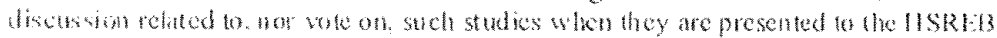


Appendix C

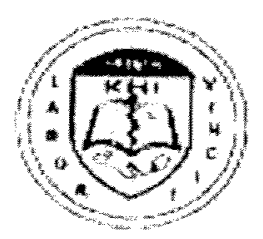

\title{
KIGALI HEALTH INSTITUTE
}

Q 3286 Kigali RWANOA

Tat $+2501572172 \cdot 250571786$

ax +250$) 571787$

Websice ntwikwa kn ac aw

E-mail wrokbins.n

Imituthanal Rewlew Board

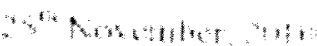

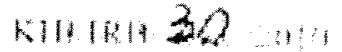

\author{
Dr. Volunda Babenko-Mould, HN, BSeN, MSCN \\ Arthur L * bult Fomily School of Nursing

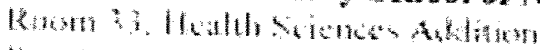

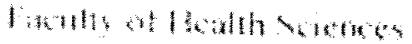

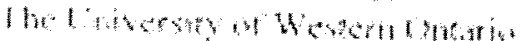

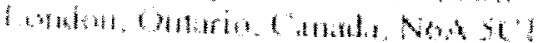

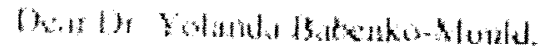

\section{IF: EXPHITHD WIITS CI.EARANCE}

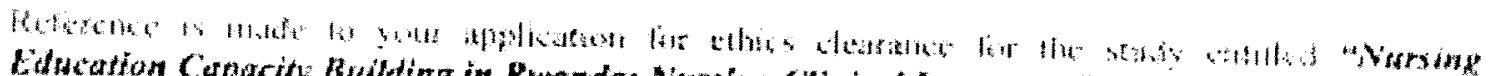

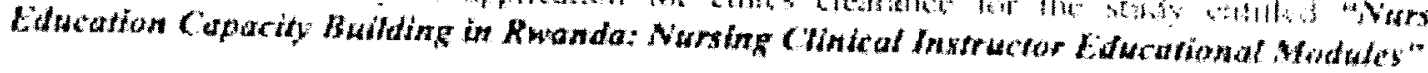

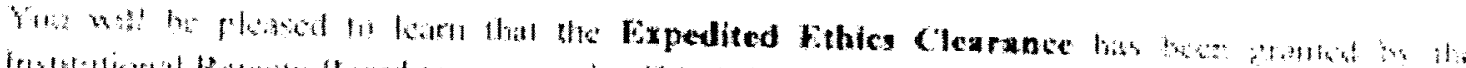

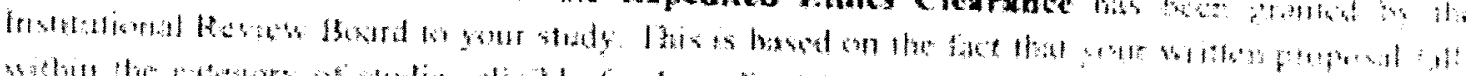

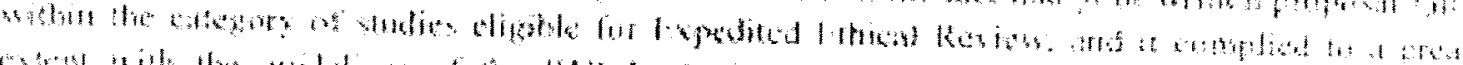

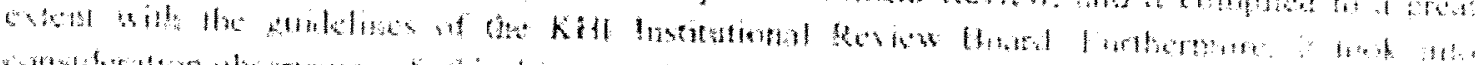

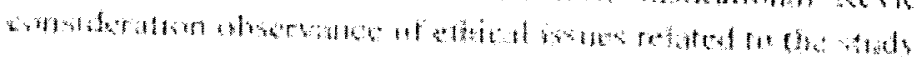

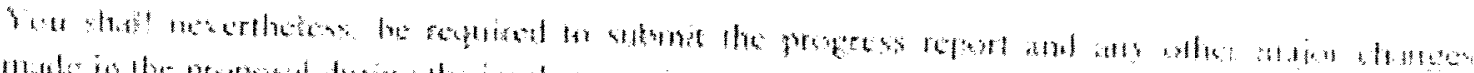

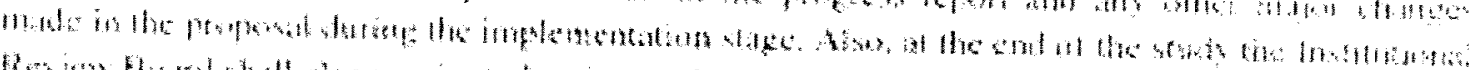

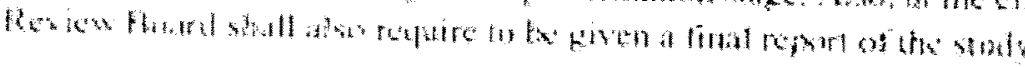

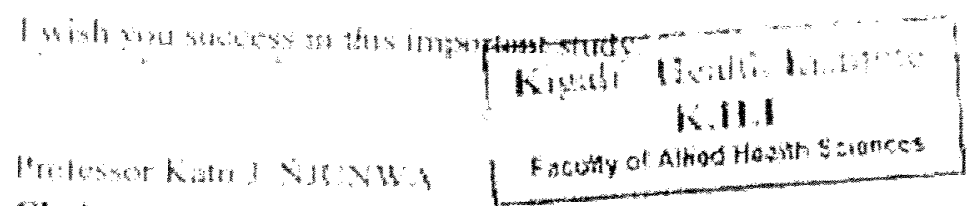

\section{Chaimerom. Klll Institutional Revicw Bourd}

$\leqslant$

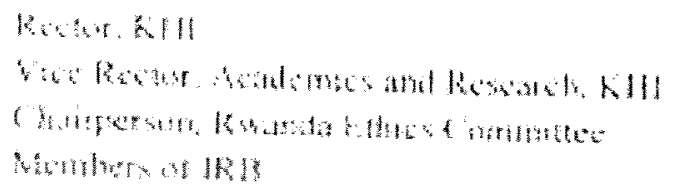




\section{Appendix D}

Letter of Information to Clinical Instructors

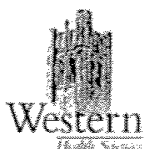

Nursing Education Capacity Building in Rwanda: Clinical Instructor Education Modules

Dear Colleagues,

We are writing to ask you to participate in a research study titled Nursing Education Capacity Building in Rwanda: Cinical instructor Education Modules. The overall purpose of the study is to explore nursing clinical instructor's' knowledge of, and self-efficacy for clinical teaching before and after use of educational modules. Furthermore, we wish to understand nursing clinical instructors' perceptions of the utility of the educational modules.

In the first stage of the study, we would like to interview you to gain an understanding of your ideas about the role and responsibilities of the nursing clinical instructor, evaluation of students in the clinical setting, and clinical teaching. The interview will require approximately 90 minutes of time. Nursing clinical instructors who volunteer to participate in the first interview will be compensated for their time.

In the second stage of the study, we would like you to a) complete three clinical instructor educational modules and b) participate in an interview after completing the modules to gain further insights about the extent to which ideas evolved about clinical teaching, evaluation of students, and clinical instructor roles and responsibilities. Completion of the three educational modules will require about 3 hours of your time. The second interview will require about 90 minutes of time. Completion of the modules and second interview will take place on the same day. The educational modules will be available on DVD for the participating nursing clinical instructors to complete. If you volunteer to participate in completing the educational modules and the second interview, you will be compensated for your time.

Nursing clinical instructors eligible to participate in this study are those who are employed as clinical instructors at the Kigali Health Institute, and who are able to speak and read English. If you would like more information, or are interested in participating in this study, you may contact the study coordinator, Germaine Tuyisenge at: Nursing clinical instructors who contact the researchers by phone or email, or Germaine Tuyisenge by email, with their permission to participate, will constitute their consent.

If you consent to participate in the study, a member of the research team will contact you to arrange a time for the first interview and second interviews, which will be recorded and then transcribed by researchers, and for the completion of the educational modules. During the first interview, you will be asked to share information about your knowledge of and self-efficacy (confidence) for clinical teaching. roles and responsibilities, and evaluation of student performance. At the end of the first interview you will be asked for some demographic data, and a date and time will be scheduled for completion of the modules and for the second interview. At the end of the first interview, you will be compensated for your time. 
A research team member will arrange for a quiet space for you to complete the educational modules. After you have completed the modules, a research team member will conduct the second interview with you in a quiet location. This interview will also be recorded and transcribed for the reseatchers. The modules will take approximately 3 hours to complete, and the second interview will take about 90 minutes. The module completion and second interview will be arranged to take place on the same day. At the conclusion of the second interview, you will be compensated for your time for completing the educational modules and the second interview.

We will need to record your name and emall address so that a research team member may contact you to schedule dates and times for interviews and module completion. Once the second interviews have been transcribed by the research team and the data analysis process is underway, all contact information will be deleted from the research assistant's computer and any hardcopy will be shredded. No identifying information will be linked to participants' responses. No one will be informed as to whether or not you have participated in the study. Only the research team will have access to the interview data. All data will be reported as grouped data with no disclosure of your identity or location of clinical teaching. All data will be destroyed after five years.

Participation in this study is voluntary. You may refuse to participate, as well as refuse to answer any questions. There are no known risks associated with this study. A benefit to participation in this study is an opportunity to gain further knowledge of, and self-efficacy (confidence) for clinical teaching, roles and responsibilities, and evaluation of student performance. $A$ benefit also includes sharing your perceptions about the utility of the educational modules.

Anytime during the study, you can contact Dr. Yolanda Babenko-Mould

answer any questions or concerns you have about the study. You can also contact the University of Western Ontario Office of Research Ethics in Canada at y email a* you have any questions about your rights in this research project.

Sincerely,

Yolanda Babenko-Mould, RN, PhD

Assistant Professor

Arthur Labatt Family

School of Nursing

Faculty of Health Sciences

The University of Western Ontario

London, Ontario, Canada

NGA 5 C1
Carroll Iwasiw, RN, EdD

Professor

Arthur Labatt Family

School of Nursing

Faculty of Health Sciences

The University of Western Ontario

London, Ontario, Canada

N6A 5 C1
Mary-Anne Andrusyszyn, RN, EdD Professor and Director Arthur Labatt Family School of Nursing Faculty of Health Sciences The University of Western Ontario London, Ontario, Canada NGA SCI 


\section{CURRICULUM VITAE}

\section{MARY ELIZABETH THUSS}

Education:

McMaster University

Doon Campus/Kitchener, Ontario, Canada

2007-2011 BScN Graduated with Honors

Conestoga College

Kitchener, Ontario, Canada

2006-2007 Upgrading to Registered Practical Nurse Diploma

Conestoga College

Guelph, Ontario, Canada

1974-1976 Registered Nursing Assistant Certificate

Work Experience: Clinical Instructor

Western University

2013-2014

Teaching Assistant

Western University

2012-2013

Registered Practical Nurse

London Health Sciences Centre

London, Ontario

2002-2011 